\title{
EchoGéo
}

$26 \mid 2013$

Varia

\section{Aléas et risques naturels dans l'intérieur semi-aride du Nordeste brésilien : la crue-éclair du Rio Grangeiro (Crato, Ceará) du 28 janvier 2011}

Alexsandra de Oliveira Magalhães et Jean-Pierre Peulvast

\section{CpenEdition}

Journals

Édition électronique

URL : https://journals.openedition.org/echogeo/13596

DOI : 10.4000/echogeo.13596

ISSN : 1963-1197

Éditeur

Pôle de recherche pour l'organisation et la diffusion de l'information géographique (CNRS UMR 8586)

Référence électronique

Alexsandra de Oliveira Magalhães et Jean-Pierre Peulvast, " Aléas et risques naturels dans l'intérieur semi-aride du Nordeste brésilien : la crue-éclair du Rio Grangeiro (Crato, Ceará) du 28 janvier 2011 », EchoGéo [En ligne], 26 | 2013, mis en ligne le 19 décembre 2013, consulté le 01 août 2021. URL : http:// journals.openedition.org/echogeo/13596 ; DOI : https://doi.org/10.4000/echogeo.13596

Ce document a été généré automatiquement le 1 août 2021

EchoGéo est mis à disposition selon les termes de la licence Creative Commons Attribution - Pas d'Utilisation Commerciale - Pas de Modification 4.0 International (CC BY-NC-ND) 


\title{
Aléas et risques naturels dans l'intérieur semi-aride du Nordeste brésilien : la crue-éclair du Rio Grangeiro (Crato, Ceará) du 28 janvier 2011
}

\author{
Alexsandra de Oliveira Magalhães et Jean-Pierre Peulvast
}

\section{Introduction}

1 Plusieurs graves crues ont affecté le Nordeste brésilien ces dernières années (ex: Pernambuco, Alagoas, janvier 2010). Celle du Rio Grangeiro, qui a provoqué d'importants dommages dans le centre-ville, le 28 janvier 2011, est un exemple de ces événements brutaux qui menacent de plus en plus les biens, les infrastructures et les personnes. Malgré la répétition récente de telles catastrophes, ici et dans d'autres régions du Brésil (État de Rio de Janeiro, janvier 2010 et 2011), il n'existe guère de «culture» (Glastron, 2003) ou même d'appréhension locale des risques, ni aucune expression de cette problématique dans l'aménagement et la planification urbaine (Magalhães et al., 2010). Dans la littérature scientifique, il n'existait jusque récemment que quelques travaux sur des crues et des mouvements de terrain de petite taille affectant les systèmes de vallées et d'interfluves qui forment le site urbain (Ribeiro \& Guerra, 2003 ; Soares, 2006 ; Carvalho \& Ribeiro, 2007).

2 La connaissance des aléas a commencé à s'étendre avec l'identification de grands mouvements de masse ayant affecté l'escarpement (glissements) et les fonds de vallées (coulées de débris), probablement avec des temps de récurrence assez longs pour que ces événements soient jusqu'alors restés ignorés (Peulvast et al., 2011). En revanche, les crues et, en particulier, les crues-éclair, sont beaucoup plus fréquentes. Elles restent pourtant mal étudiées et gérées, en dépit des nombreuses annonces faites après chaque 
inondation. L'objectif de ce travail est donc de contribuer à combler cette lacune, à partir d'une étude de cas portant sur la crue-éclair et l'inondation du 28 janvier 2011. Après une présentation du secteur étudié et des méthodes utilisées, l'article décrit cette crue, ses causes, son déroulement et ses conséquences, puis analyse les facteurs naturels et anthropiques en cause, reprenant en partie une démarche systémique suivie, entre autres, dans une étude menée par Menad et al. (2012) sur l'inondation de 2001 à Bab-el-Oued (Alger, Algérie). Il aboutit à une réflexion sur le caractère de moins en moins exceptionnel de tels événements dans le contexte d'une urbanisation mal contrôlée qui modifie la formation et les modalités des écoulements, tout en aggravant les menaces sur les biens et les personnes. Cette réflexion porte aussi sur le rôle essentiel de la connaissance géographique pour la prise en compte de la question des risques naturels dans le processus d'urbanisation à l'intérieur du Nordeste brésilien.

\section{Présentation du secteur étudié}

\section{Le contexte géographique et le bassin-versant du Rio Grangeiro}

3 L'État du Ceará, dans le Nordeste brésilien, présente une mosaïque complexe de paysages, du littoral subhumide jusqu'aux plaines et aux montagnes du sertão semiaride. Au sud de l'État, dans la région du Cariri, le haut plateau appelé Chapada do Araripe forme un îlot humide et forestier contrastant avec la sécheresse de la dépression et des plaines environnantes (illustration 1). Bénéficiant de ces conditions favorables, la région métropolitaine du Cariri abrite une population en forte croissance sur le piémont NE de la Chapada. En conséquence apparaissent des problèmes environnementaux préoccupants, liés aux impacts de cette occupation légale ou non de l'espace (déforestation, terrassements, exploitation anarchique des ressources hydriques, canalisation des cours d'eau, imperméabilisation des sols, pollution...) et aux risques encourus par la ville et ses habitants en relation avec le fonctionnement et les perturbations du milieu naturel. 


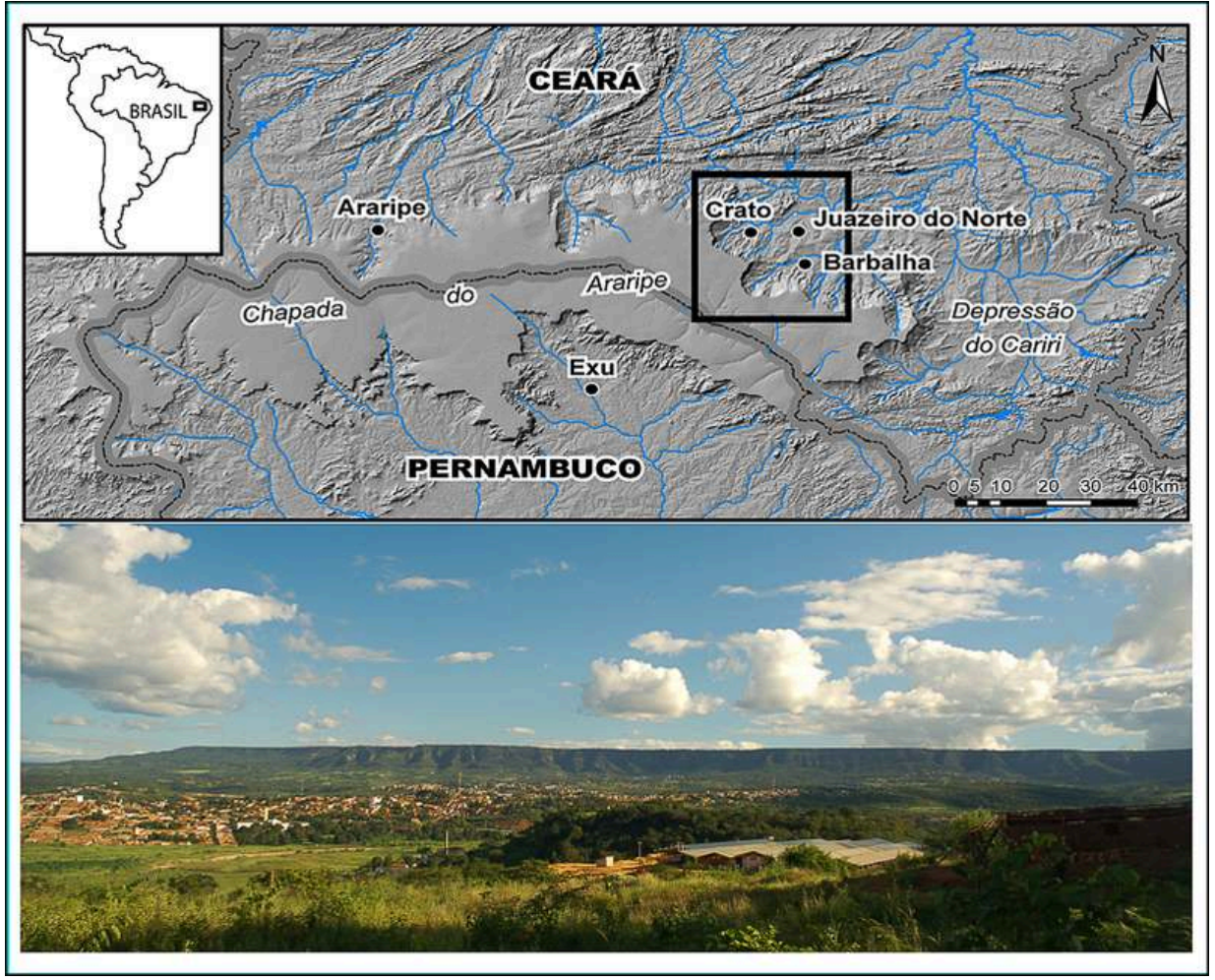

Source : d'après Peulvast et al., 2011

4 La Chapada do Araripe forme un plateau allongé $\mathrm{EW}$ sur $120 \mathrm{~km}$ entre $39^{\circ} 00^{\prime}$ et $40^{\circ} 50^{\prime} \mathrm{W}$, et $7^{\circ} 05^{\prime}$ et $7^{\circ} 39^{\prime} \mathrm{S}$, à la frontière entre les États du Ceará et du Pernambuco. Il s'agit de l'un des massifs humides (brejos de altitude) qui s'élèvent au-dessus des plaines semiarides du sertão nordestin (Cavalcante, 2005). Avec des altitudes de 900 à $1002 \mathrm{~m}$, sa partie orientale est délimitée par un escarpement spectaculaire de type cuesta; elle domine la dépression périphérique du Cariri, au nord de laquelle se relèvent les reliefs du socle (Serra de São Pedro). Exposé aux alizés, l'escarpement porte des forêts sempervirentes et semi-décidues typiques d'un climat tropical subhumide. Dans le secteur étudié comme tout autour de la partie orientale de la Chapada, une haute corniche gréseuse domine des glacis disséqués, façonnés dans des roches plus tendres, au fond de deux vastes amphithéâtres d'érosion ouverts au NE (Crato, Barbalha; Peulvast et al., 2011).

5 Le Rio Grangeiro est l'un des cours d'eau subparallèles qui dissèquent les glacis de piémont de la Chapada do Araripe, dans le rentrant érosif de Crato (illustration 2). Orientés au NE vers la gouttière WE qui rassemble les eaux venues de la chapada et du flanc nord de la dépression du Cariri (Rio da Batateira, Rio Salgado), ces bassinsversants sont allongés. Pour une superficie de $20,96 \mathrm{~km}^{2}$, celui du Rio Grangeiro atteint $10,3 \mathrm{~km}$ de longueur en ligne droite, de la Chapada jusqu'au confluent avec le Rio da Batateira. Sa largeur ne dépasse pas 1,5 à 2 km (Ribeiro, 2004 ; Lima Neto et al., 2008). Cette disposition, que l'on retrouve pour les drains voisins (Rio da Batateira amont, Riacho Saco Lobo, Riacho Constantino), reflète pour tous ces cours d'eau un faible degré de hiérarchisation de systèmes de drainage parallèles et encaissés de quelques dizaines de mètres sur une courte distance ( $3-4 \mathrm{~km})$, le long de ligne de plus grande pente des glacis, vers la partie aval du Rio da Batateira (illustration 2). 
Illustration 2 - Carte topographique du rentrant érosif de Crato et du bassin-versant du Rio Grangeiro

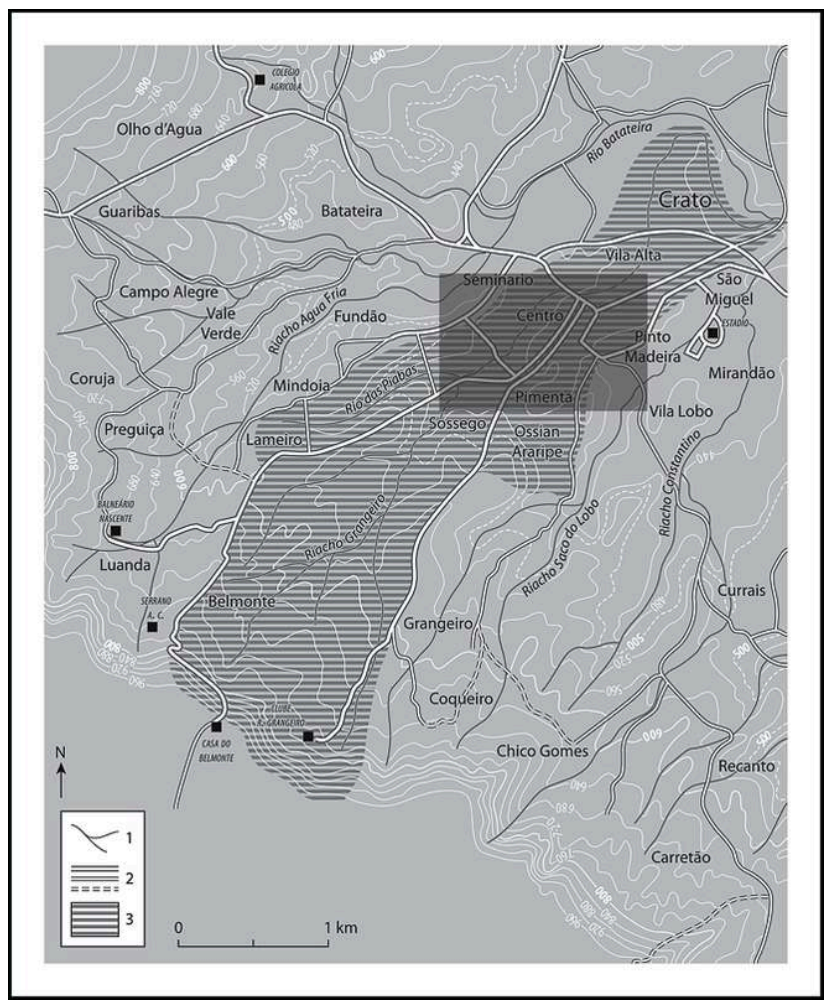

Légende : 1. Cours d'eau ; 2. Principales routes ; 3. Bassin-versant du Rio Grangeiro. Base : FUNDETEC, 1999.

Dans le bassin-versant du Rio Grangeiro, les fonds de vallée présentent des formes en berceau à l'amont, où ils sont pour la plupart déconnectés des grands entonnoirs de sapement abrupts qui échancrent l'escarpement. Ils se resserrent dans la partie moyenne, la plus encaissée (quartiers Lameiro, Sossego et Pimenta). Le chenal principal, encadré par des basses terrasses étroites constituées d'alluvions très hétérométriques et riches en gros blocs à peine émoussés (terrasses de coulées de débris ou de laves torrentielles), s'élargit ensuite, brusquement, à l'aval du centre-ville de Crato. À partir de là, le cours d'eau décrit un vaste méandre encaissé dans sa basse terrasse ici sableuse avant de confluer avec le Rio da Batateira.

7 Les données sur le régime hydrologique du Rio Grangeiro sont parcellaires, en l'absence de mesures systématiques de débit. Il ne s'y écoule pratiquement pas d'eau pendant une partie importante de l'année, malgré le nombre (4) et l'importance des sources situées au pied de la Chapada. En effet, ces sources issues de l'aquifère gréseux ont été captées au moyen d'un système complexe et anarchique de tuyaux d'adduction d'eau le plus souvent privés et de canaux de terre (levadas) destinés à l'irrigation et aux loisirs (piscines). De ce fait, le ruisseau est privé de la plus grande partie d'un débit de base sur lequel aucune donnée n'est d'ailleurs disponible (Ribeiro, 2004). Les parties moyennes et aval du cours écoulent donc surtout les eaux usées des égouts et les eaux pluviales; en cas de fortes pluies, la concentration rapide de ces dernières et leur acheminement en ville par un canal étroit et pentu expliquent la brutalité du comportement 
hydrologique de ce drain. Les affluents (Riacho das Piabas, en rive gauche, près du pont de Lameiro et Riacho da Vala, en rive droite) présentent les mêmes caractéristiques.

\section{Urbanisation accélérée}

8 Parmi les trois villes principales de la région du Cariri (Crato, Juazeiro do Norte, Barbalha), la ville de Crato (120 000 habitants) est la plus proche de l'escarpement qui délimite le plateau. Fondée au XVIII ${ }^{e}$ siècle sur les rives du Rio Grangeiro, l'un des cours d'eau descendus de l'escarpement, elle s'étend de façon plus ou moins désordonnée vers l'amont, principalement le long de ce torrent et sur les interfluves découpés par ses affluents et ses voisins dans un large glacis de piémont. La ville s'est peu à peu étendue, gagnant les interfluves adjacents et, plus récemment, les contreforts de l'escarpement. Depuis les années 1970, avec l'accroissement de la spéculation immobilière, d'anciens secteurs ruraux se sont urbanisés et la place des espaces naturels a reculé au profit d'implantations plus ou moins organisées. Il existe encore, principalement dans les vallons de la partie SW du bassin-versant (Lameiro-Belmonte) de larges secteurs ruraux, occupés par une végétation secondaire, entre de petites exploitations agricoles. Le facteur principal de l'expansion urbaine en bas de l'escarpement fut l'installation de clubs récréatifs (Clube Recreativo Granjeiro, Sociedade do Clube Serrano Atlético Cratense, AABEC - Associação Atlética Banco do Estado do Ceará, Itaytera Clube, Passárgada, etc.), un peu en contrebas des sources. Par la suite, une partie de la base de l'escarpement fut lotie pour la construction de maisons de villégiature ou de propriétés de luxe et, plus récemment, pour l'implantation de domaines résidentiels fermés (condomínios fechados). Ce qui fit de ces espaces les quartiers nobles de la ville, les valorisant comme des espaces urbains (Ribeiro, 2004), principalement dans les parties amont des vallées des rios Grangeiro, das Piabas et Agua Fria-Batateira (Luanda ; illustration 2).

\section{Les risques naturels : une prise de conscience récente?}

9 Les risques naturels dans cette région sont en grande partie négligés par le Plan Directeur Municipal, mais posent un problème réel. Aucune catastrophe meurtrière et de grande ampleur n'y est recensée. Cependant, après bien d'autres crues importantes (au moins une chaque année sur la période 2002-2011, dont une ayant fait une victime, en mars 2005), la crue du 28 janvier 2011 est venue rappeler qu'une partie des bas quartiers de la cité est menacée, là où les deux cours d'eau qui la traversent sont contenus dans d'étroits canaux ou même dans des buses de béton (Riacho da Vala) construits dans les années 1990-2000. L'ampleur des dégâts qu'elle a provoqués, en ville comme sur le canal, jointe à son impact médiatique, psychologique, politique et financier, entraînant un effort inédit d'enregistrement et de documentation, justifie le choix de cette crue particulière comme objet d'étude.

10 À l'amont, les quartiers proches de la Chapada do Araripe sont exposés aux risques liés à des mouvements de masse plus rares, mais potentiellement plus dangereux encore, qui peuvent affecter l'escarpement et son piémont. Des modelés caractéristiques (loupes et lobes de débris, terrasses...) et des dépôts attribués à de grands mouvements de masse (glissements, coulées de débris) ont été reconnus ici comme dans l'ensemble du rebord et du piémont de la partie orientale de la Chapada do Araripe (Peulvast et al., 2011). Leur âge et leur fréquence sont encore inconnus mais ils figurent parmi les aléas 
naturels à prendre en compte. Dans l'immédiat, ce sont cependant les risques liés aux crues, en particulier celles du Rio Grangeiro, qui retiennent le plus l'attention.

\section{Protocoles méthodologiques}

11 L'étude repose sur une analyse des précipitations, de la crue et de l'inondation qui se sont produites le 28 janvier 2011. L'événement a d'abord été comparé à d'autres événements antérieurs à partir de recherches bibliographiques, principalement dans la presse écrite depuis 2002 (Jornal do Cariri, Diario do Nordeste, O Povo). L'événement luimême a été analysé à partir de documents audiovisuels (télévision, vidéos amateur, reportages photographiques, blogs), complétés par la collecte de données d'ordre météorologique et hydrologique. Des documents sur la gestion de la catastrophe ont été obtenus de différents organismes d'État (Fundação Cearense de Meteorologia FUNCEME, Companhia de Gerenciamento de Recursos Hídricos do Ceará - COGERH, Instituto Nacional de Meteorologia - INEMET, Coordenadoria Estadual de Defesa Civil CEDEC, Corps de Pompiers militaires, etc.) ainsi que de la mairie (Prefeitura Municipal do Crato : Secretaria Municipal do Meio Ambiente). Parmi les documents utilisés figurent le Plano Diretor do Município do Crato ainsi que divers documents cartographiques et données officielles.

L'étude repose aussi sur des travaux de terrain réalisés par nous dans la région depuis 2004, avant et après la crue. L'analyse de cartes (en particulier aux échelles 1/50 000 et $1 / 10000)$ a été complétée par celle d'images 3D de Google Earth $(2005,2009)$ et de photographies au sol de dates variées, avant, pendant et après l'événement. Les données obtenues à partir de l'analyse des photos, vidéos et reportages ont été utilisées pour cartographier l'inondation du centre-ville, afin d'identifier les secteurs touchés et de les rapporter à la topographie ainsi qu'aux éléments permettant de caractériser la vulnérabilité des différents quartiers et installations. Enfin, la consultation des nouvelles et comptes rendus à travers les médias, celle des rapports techniques rédigés après la crue, ainsi que les contacts pris avec la population et les acteurs concernés (politiques, techniciens, représentants d'associations) à différents niveaux (Fédération, État, commune), ont permis de compléter les données et de prendre un recul critique par rapport aux informations immédiates.

\section{L'événement du 28 janvier 2011 : précipitations, crue et inondations dans le bassin-versant du Rio Granjeiro}

13 Généralement, les précipitations les plus importantes dans le Ceará commencent chaque année en décembre et peuvent durer jusqu'en juin ou juillet, selon les conditions océaniques et atmosphériques régionales. Les pluies qui tombent en décembre et janvier sont appelées chuvas de pré-estação (pluies d'avant-saison), et se produisent principalement dans la région du Cariri. Ces pluies et celles de la saison des pluies sont influencées par les conditions locales, régionales et globales. Parmi celles-ci, les phénomènes El Niño et La Niña, la température de l'Atlantique tropical, les alizés de $\mathrm{NE}$ et $\mathrm{SE}$, entre autres, sont considérés comme facteurs déterminants, contribuant ou non à la formation de nuages et de précipitations sur l'État (INPE, 2011). Nous décrivons 
ici l'événement pluvieux du 28 janvier 2011 survenu à Crato et l'inondation correspondante.

\section{L'événement pluvieux}

14 Les précipitations qui ont atteint la commune de Crato le 28 janvier 2011, provoquant le chaos, la panique et des destructions dans la ville, ont amené le maire de l'époque, Samuel Araripe, à décréter immédiatement l'état d'urgence. Selon le bulletin de la Fundação Cearense de Meteorologia e Recursos Hídricos (FUNCEME, 2011), la pluie fut de $162 \mathrm{~mm}$, et tomba au petit matin, pratiquement sans interruption pendant 6 heures (Relatório dos Bombeiros/Defesa Civil). Alors que beaucoup de personnes dormaient, la pluie a provoqué une grosse crue torrentielle du Rio Grangeiro, la destruction partielle du canal qui traverse la ville et l'inondation d'une partie du centre.

Le graphique des précipitations journalières de janvier à mai 2011 sur la station de Crato, située en zone urbaine à $427 \mathrm{~m}$ d'altitude montre une concentration des pics sur quelques jours de chaque mois (illustration 3), avec des totaux mensuels de $392,8 \mathrm{~mm}$ en janvier, 331,4 $\mathrm{mm}$ en février, 192,4 $\mathrm{mm}$ en mars, 133,4 $\mathrm{mm}$ en avril et $88 \mathrm{~mm}$ en mai. Le pic le plus important correspond au 28 janvier 2011 (162 mm); ce même jour, $137 \mathrm{~mm}$ ont été mesurés à la station de Lameiro, plus proche de la Chapada. Il avait déjà plu abondamment les jours précédents $(74,7 \mathrm{~mm}$ les 25 et 26 janvier) ce qui implique que le niveau des nappes avait déjà pu s'élever et que les sols étaient humides, saturés ou proches de la saturation. Ceci a pu diminuer l'infiltration et augmenter les coefficients de ruissellement.

Illustration 3 - Précipitations journalières de janvier à mai 2011

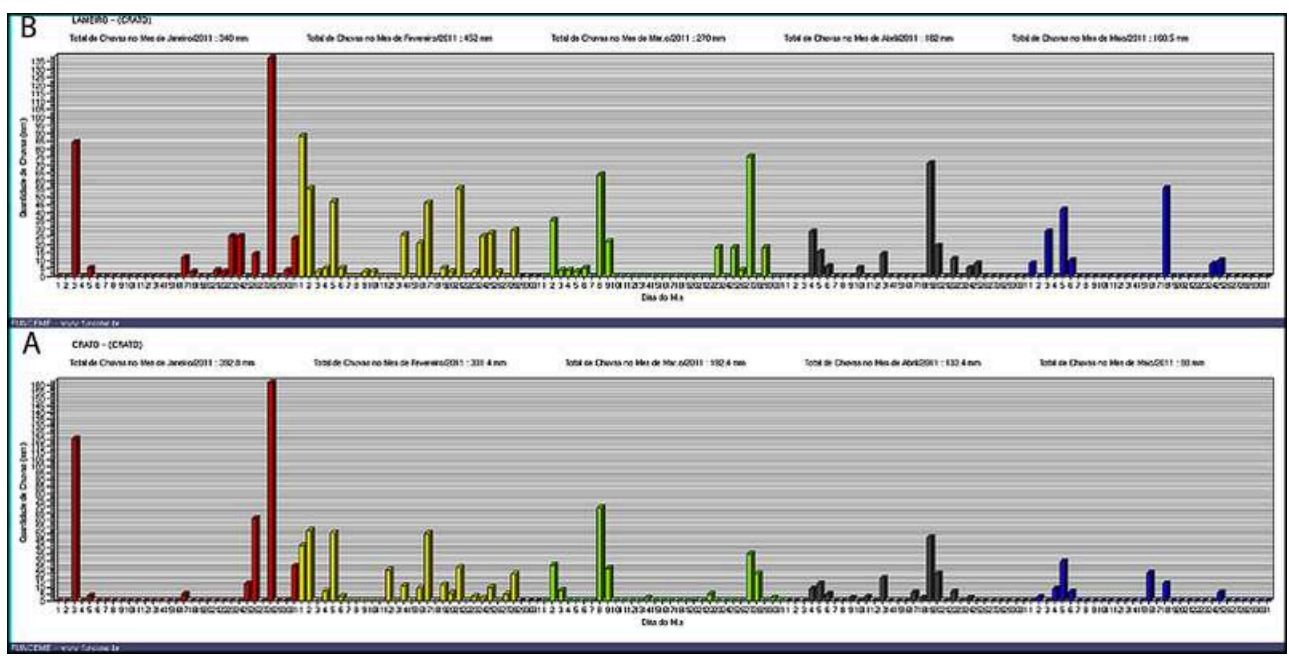

A : station de Crato ; $\mathrm{B}$ : station de Lameiro

Source : FUNCEME.

La consultation des bulletins météorologiques des jours précédents montre que cet événement pluvieux n'avait pas été prévu et ne pouvait donc pas avoir été anticipé. Tout au plus les analyses faites mi-janvier à l'échelle du pays (Melo, 2011) indiquentelles que, compte-tenu de la persistance du phénomène La Niña en cette période de l'année, la situation était favorable à la chute de pluies sur le secteur nord du Nordeste brésilien. Pourtant, des températures supérieures à la normale sur l'Atlantique tropical 
nord auraient pu au contraire empêcher la formation de précipitations, surtout dans le secteur nord où prédomine normalement l'action de la Zone de Convergence Intertropicale (ZCIT) en cette période de l'année. Le bulletin de prévisions du 27 janvier (Instituto Nacional de Pesquisas Espaciais, INPE) indique une situation de marais barométrique sur tout le pays. Un phénomène d'instabilité locale auto-entretenu semble avoir provoqué l'événement pluvieux du 28 janvier 2011. C'est ce que confirme l'examen heure par heure des images satellitaires GOES 12 (canal 4, INPE), où l'on voit la naissance rapide d'un système nuageux et orageux localisé sur le SE du Ceará le 28 janvier à 1 heure du matin. La croissance de ce système est ensuite rapide, jusqu'à un diamètre de plus de $200 \mathrm{~km}$ à 7 heures du matin, accompagnée d'une lente dérive vers l'W ou l'WNW, donc vers le Cariri et la bordure E de la Chapada (illustrations 4A à 4D). Ces conditions, accompagnées de forts vents locaux dans le système convectif, ont pu amplifier le phénomène par un effet orographique sur le versant au vent de la Chapada.

Illustration 4A - Séquence de développement des systèmes nuageux et orageux dans la nuit du 27 au 28 janvier 2011 , à $1 \mathrm{~h}$

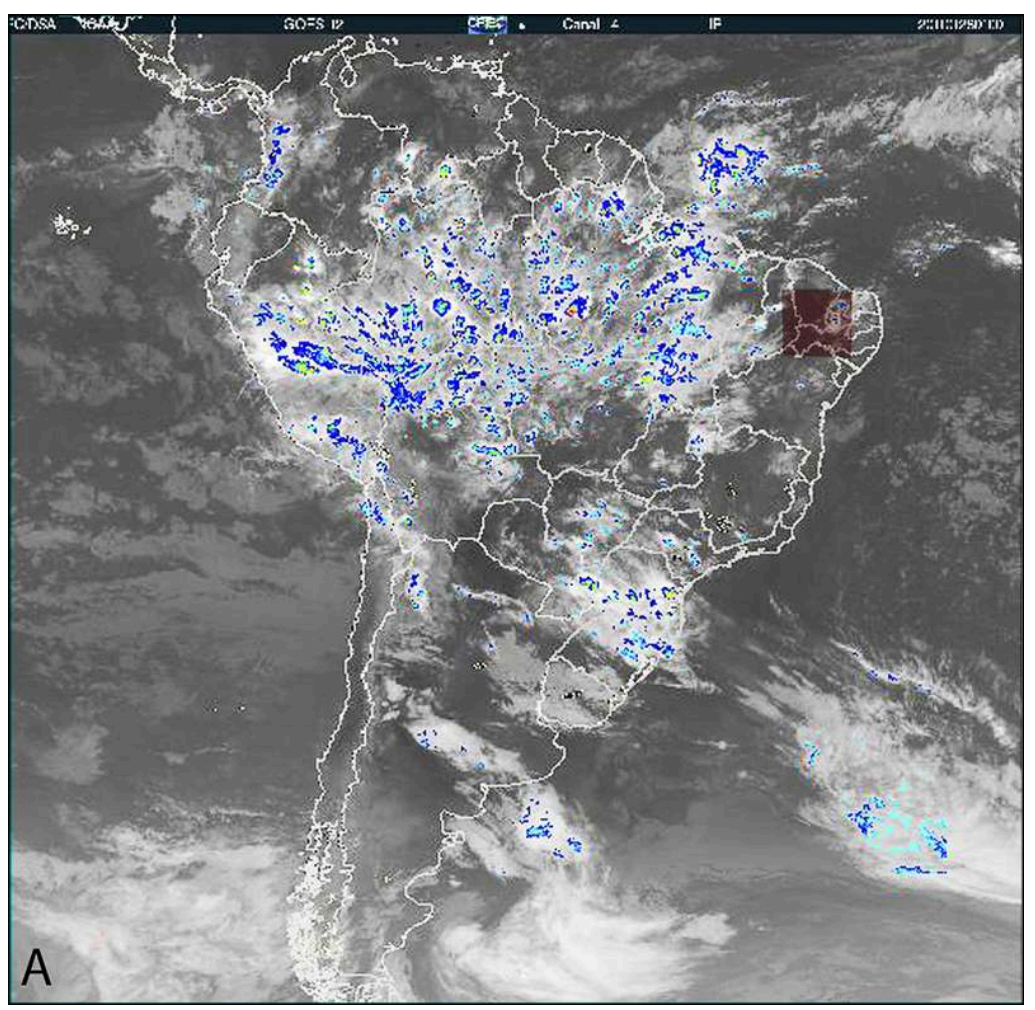

Le carré rouge indique le secteur concerné par l'étude.

Source : Images satellitaires GOES 12 (canal 4, INPE, 2011).

Illustration 4B - Séquence de développement des systèmes nuageux et orageux dans la nuit du 27 au 28 janvier 2011, à $3 \mathrm{~h}$ 


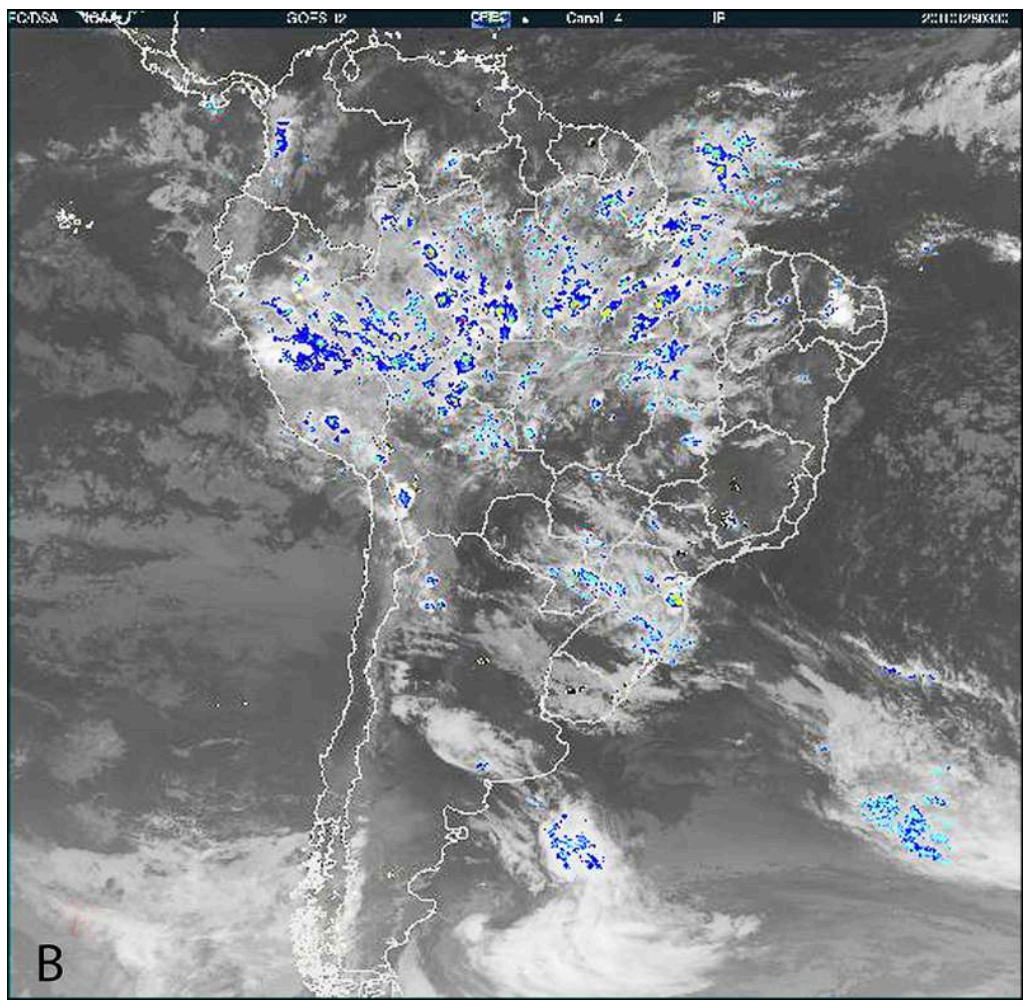

Source: Images satellitaires GOES 12 (canal 4, INPE, 2011).

Illustration 4C - Séquence de développement des systèmes nuageux et orageux dans la nuit du 27 au 28 janvier 2011, à $6 \mathrm{~h}$

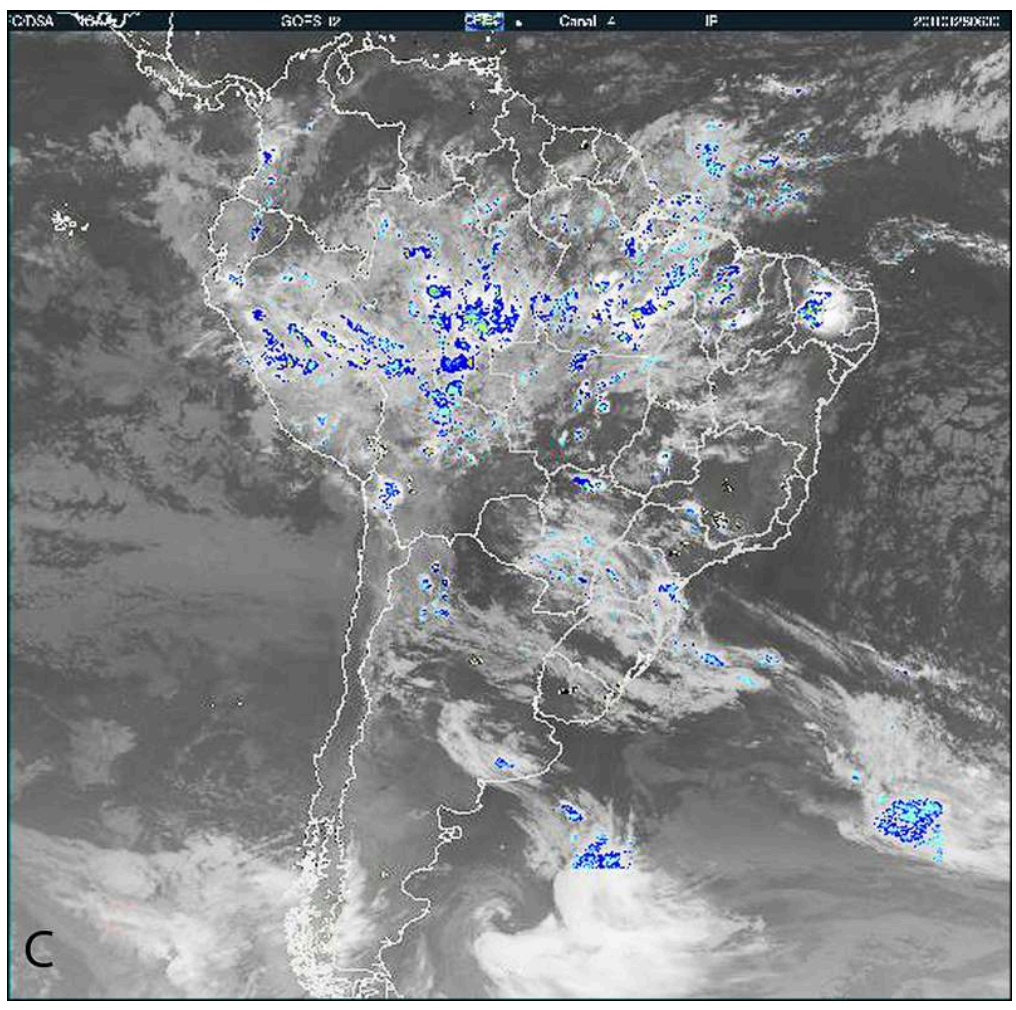

Source: Images satellitaires GOES 12 (canal 4, INPE, 2011). 
Illustration 4D - Séquence de développement des systèmes nuageux et orageux dans la nuit du 27 au 28 janvier 2011, à $8 \mathrm{~h}$

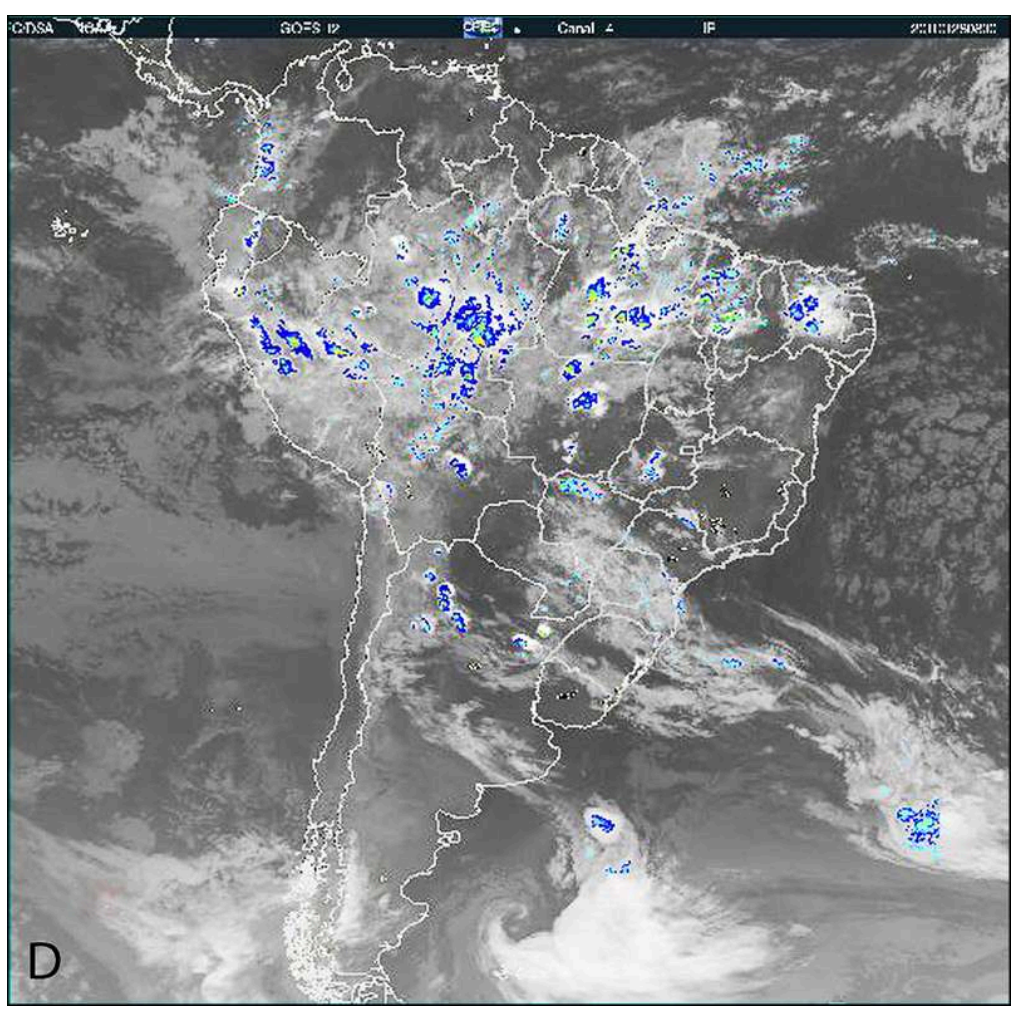

Source : Images satellitaires GOES 12 (canal 4, INPE, 2011).

\section{La séquence pluviométrique antérieure à la crue}

L'analyse des données de la FUNCEME, obtenues à partir des deux stations météorologiques de Crato et de Lameiro, permet de prendre en compte le total des précipitations qui ont précédé le déclenchement de la crue en préparant éventuellement certaines de ses conditions (par exemple, la saturation des sols).

18 À Lameiro (illustration 5B), $267 \mathrm{~mm}$ sont tombés en décembre 2010, en 9 jours : 9 décembre $(21 \mathrm{~mm}), 10$ décembre $(65 \mathrm{~mm}), 12$ décembre $(12 \mathrm{~mm}), 13$ décembre $(5 \mathrm{~mm})$, 14 décembre $(36 \mathrm{~mm}), 17$ décembre $(42 \mathrm{~mm}), 18$ décembre $(63 \mathrm{~mm}), 19$ décembre ( $5 \mathrm{~mm}$ ) et 20 décembre $(18 \mathrm{~mm})$. De son côté, la station de Crato a reçu 193,6 $\mathrm{mm}$ en décembre 2010 (illustration $5 \mathrm{~A}$ ). Les jours les plus arrosés ont été les 9 décembre $(30 \mathrm{~mm}), 10$ décembre $(40 \mathrm{~mm}), 11$ décembre $(12,6 \mathrm{~mm}), 13$ décembre $(3,2 \mathrm{~mm})$, 14 décembre $(26 \mathrm{~mm}), 15$ décembre $(0,8 \mathrm{~mm}), 17$ décembre $(35 \mathrm{~mm}), 18$ décembre $(33,8 \mathrm{~mm}), 20$ décembre $(9,4 \mathrm{~mm}), 31$ décembre $(2,8 \mathrm{~mm})$. 
Illustrations 5 - Précipitations journalières de décembre 2010 et janvier 2011

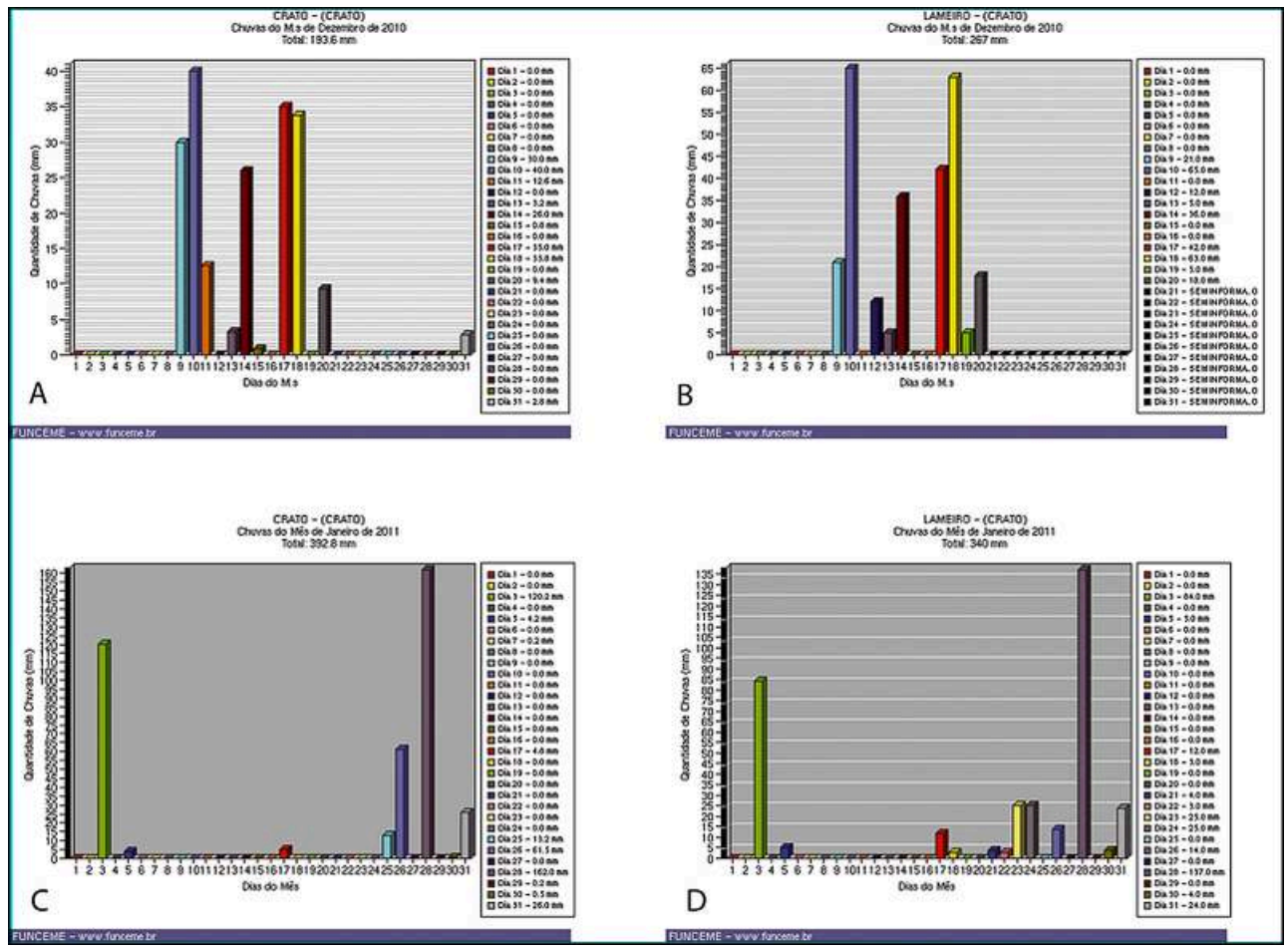

A, C : station de Crato ; B, D : station de Lameiro.

Source : FUNCEME.

19 Les totaux de janvier 2011 sont plus importants encore. À Crato-centre, le total atteint $392,8 \mathrm{~mm}$ (illustration $5 \mathrm{C}$ ) et, avant le 28 , les jours les plus pluvieux sont le 3 janvier $(120,2 \mathrm{~mm}$ - sans crue signalée), le 5 janvier $(4,2 \mathrm{~mm})$, le 17 janvier $(4,8 \mathrm{~mm})$, le 25 janvier $(13,2 \mathrm{~mm})$ et le 26 janvier $(61,5 \mathrm{~mm})$. Il tombe encore $26 \mathrm{~mm}$ le 31 janvier, deux jours après la crue.

La crue a donc été précédée par d'importantes pluies tombées deux et trois jours plus tôt, un délai qui peut être plus court que le temps de ressuyage des sols. Cependant, comme lors de chaque grosse pluie, les ruissellements les plus actifs sont surtout intervenus le long des ravines (voçorocas) et des éléments de voirie tracés le long des plus grandes pentes ou de certains talwegs, ce qui peut minorer le rôle éventuel de la séquence pluvieuse antérieure. A contrario, l'absence de crue signalée après la grosse pluie du 3 janvier ( $120 \mathrm{~mm}$, mais seulement $85 \mathrm{~mm}$ à Lameiro ; illustration 5D) peut s'expliquer par l'absence de pluie importante dans les deux semaines précédentes (depuis le 21 décembre).

\section{Analyse de l'inondation et des aires inondées}

21 La pluie du 28 janvier 2011 a provoqué le débordement du canal du Rio Grangeiro. L'inondation des rues et des maisons riveraines ainsi que de nombreux bâtiments privés et publics (église, banques, commerces, station-service, écoles et collèges) s'est accompagnée de dégâts matériels importants. De nombreuses familles se sont retrouvées sans abri, mais aucune victime ne fut à déplorer, sans doute grâce à l'horaire très matinal de l'événement qui explique que les rues n'étaient alors pas fréquentées (entre 1 heure et 7 heures du matin). Plusieurs tronçons de la partie amont 
du canal, déjà dégradés lors de crues antérieures, ont été détruits; les débris ont contribué à obstruer le cours et à augmenter le débordement.

Sur le plan hydrologique, il n'existe aucune mesure de débit permettant de quantifier le phénomène. On dispose seulement de données sur des crues anciennes (SUDENEASMIC, 1967) selon lesquelles le débit maximum à temps de retour décennal estimé pour le Rio Grangeiro à l'aval du centre-ville (par comparaison avec le Rio da Batateira, où des mesures étaient disponibles) serait de $130 \mathrm{~m}^{3} / \mathrm{s}$. Une pluie de $75 \mathrm{~mm}$ maximum pourrait engendrer une crue de fréquence annuelle, dont le débit n'est pas donné. Il est probable que les chiffres atteints lors de l'événement considéré soient supérieurs aux chiffres indiqués mais l'absence de station hydrologique empêche toute estimation sérieuse. De même, les hydrogrammes de crue n'ont été établis que pour le Rio da Batateira, mais ils ont été extrapolés au bassin-versant du Rio Grangeiro, où ils seraient symétriques de part et d'autre du pic du fait de la rapidité des temps de réponse de l'écoulement en zone urbaine.

Par exemple, le 9 avril 1963, la réponse s'est fait en 8 heures, la montée en 6 heures 30, l'écoulement pendant 17 heures, avec un coefficient d'écoulement faible (3,7\%), mais de l'ordre de $30 \%$ pour la partie aval du bassin-versant, fortement urbanisée (SUDENEASMIC, 1967).

En ce qui concerne les effets de la crue, les secteurs les plus affectés sont les quartiers Lameiro, Pimenta, Seminário et Centre, les plus proches du canal (illustration 6). Les rues du centre sont les plus régulièrement atteintes par les inondations car ce secteur est le moins élevé par rapport au talweg. Entièrement construit et imperméabilisé (bâtiments, asphalte), il correspond à l'ancienne plaine d'inondation, encadrée par les basses terrasses composées de vieux dépôts torrentiels et de coulées de débris. C'est aussi le secteur où les rues sont les plus étroites, augmentant la vitesse d'écoulement de l'eau. Les enjeux y sont les plus importants, compte tenu de la concentration de bâtiments publics - y compris la mairie - et d'établissements privés ou publics de commerce, d'artisanat et d'enseignement, outre les habitations. 
Illustration 6 - Carte du centre-ville de Crato et des zones affectées par la crue du 28 janvier 2011

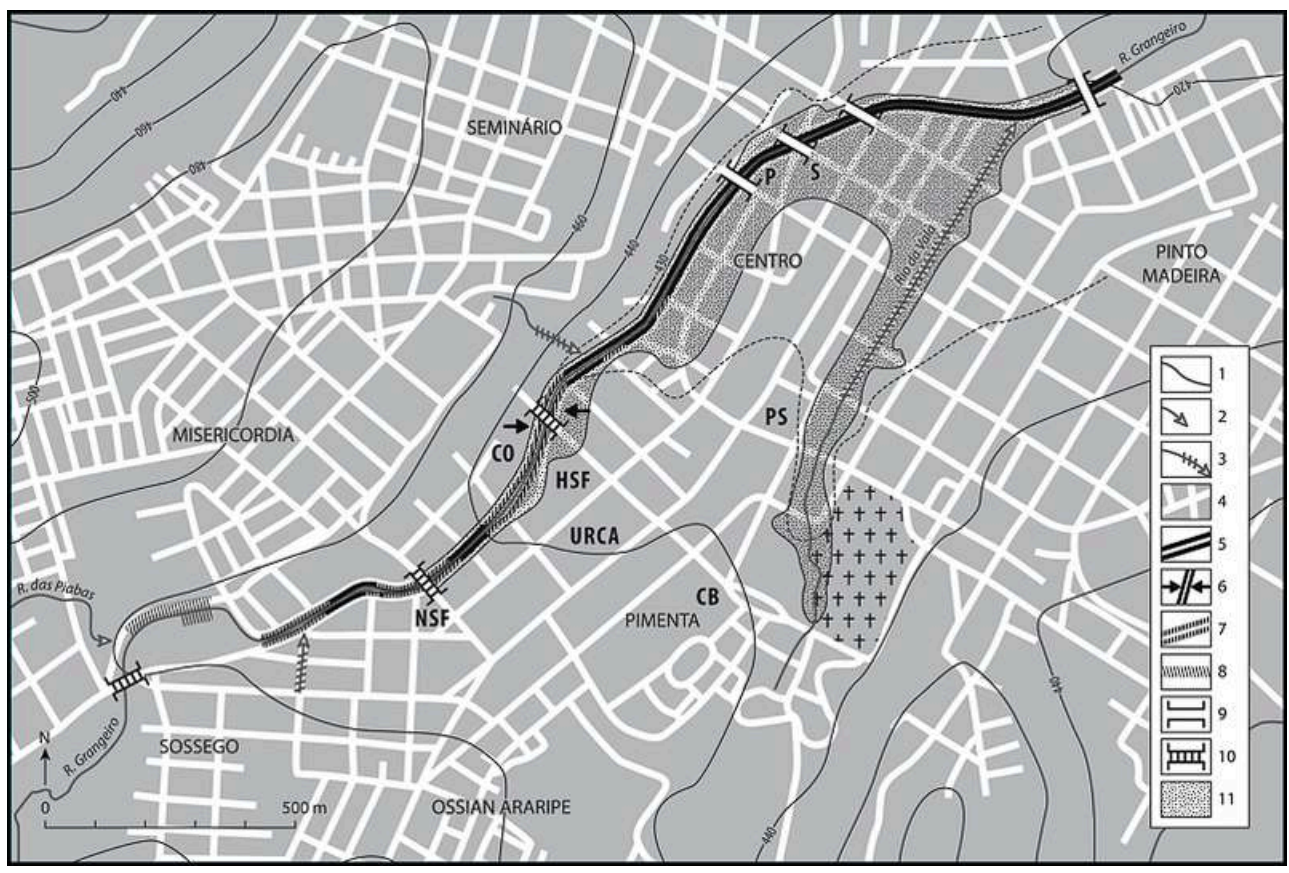

Légende : 1. Cours d'eau ; 2. Confluence aménagée ; 3. Section de cours d'eau busée ; 4. Aires construites, avec voirie en blanc ; 5 . Canal ; 6. Rétrécissement du canal ; 7 . Segment de canal endommagé ou détruit par la crue ; 8 . Erosion en berge naturelle ; 9 . Pont ; 10 . Pont dégradé ou détruit. 11. Zone inondée.

$P$ : Prefeitura Municipal (mairie). CB : Corpo de Bombeiros (pompiers). H : Hôpital São Francisco de Assis. CO : Colegio Objetivo. V : Voçoroca do Seminário. NSF : Eglise Nossa Senhora de Fátima. PS : Praça da Sé. S : Shopping Residence.

La carte au 1/10 000 de 1976 (Superitendência do Desenvolvimento do Nordeste SUDENE, 1976) montre la topographie et l'état du site avant l'extension du centre-ville aux rives du Rio Grangeiro et avant la construction du canal entre le bas du quartier Seminario et le quartier Sossego (illustration 7). La partie actuellement canalisée à l'amont du centre-ville présentait un chenal emboîté de plusieurs mètres dans la terrasse principale, alors non construite. Il ne se rapprochait du versant de rive gauche qu'au niveau du Seminário, où il décrivait un coude marqué vers l'est. En rive droite, le centre-ville était prudemment établi à 100-150 $\mathrm{m}$ du cours d'eau, sur un interfluve surélevé de $5 \mathrm{~m}$ environ par rapport à la terrasse, entre le Grangeiro et le Riacho da Vala, emboîté de quelques mètres dans la plaine de confluence. Comme lors des crues antérieures, les quartiers inondés en janvier 2011 sont exactement ceux qui occupent maintenant la basse terrasse, moins surélevée à partir du coude de Seminario, et la zone de confluence, où s'élargissaient les deux lits fluviaux aux dépens de la terrasse ici plus sensible à l'érosion (sables). 
Illustration 7 - Extrait de la carte topographique au 1/10 000 de Crato

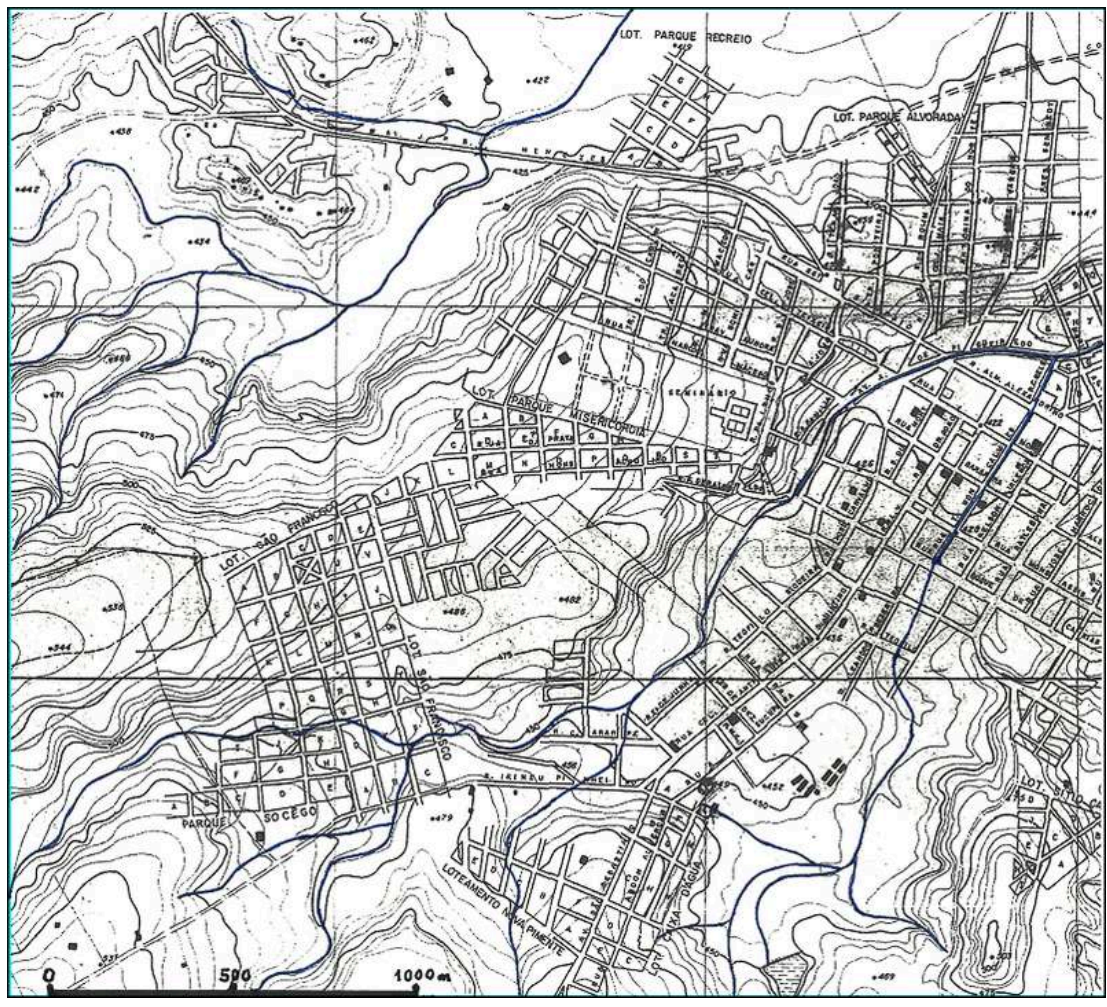

Equidistance des courbes de niveau : $5 \mathrm{~m}$.

Source : SUDENE, 1976.

La configuration du «canal» (chenal artificialisé) et des voies construites sur ses berges a contribué au phénomène d'inondation, augmentant la montée des eaux et le débordement jusque dans les rues adjacentes. Ce chenal large de $11 \mathrm{~m}$ en moyenne au sommet et de 2 à $3 \mathrm{~m}$ au fond, profond de $3 \mathrm{~m}$ en moyenne (ce qui entraîne donc une section mouillée variable : voir illustrations $8 \mathrm{~A}$ et $8 \mathrm{~B}$ ), est enjambé par 5 ponts de béton et 4 passerelles métalliques à peine surélevés. Ces ouvrages ont été submergés, constituant donc de courts segments de canalisation couverts et insuffisamment calibrés. Certains d'entre eux coïncident en outre avec des rétrécissements calés sur des ruptures de pente naturelles (emboîtement accru dans la basse terrasse à l'amont de Seminário, peut-être à l'emplacement du terminus de l'ancienne coulée de débris formant la terrasse ; illustration 8B). 
Illustration 8A - Le canal du Rio Grangeiro à l'aval de la mairie : géométrie et défauts d'entretien

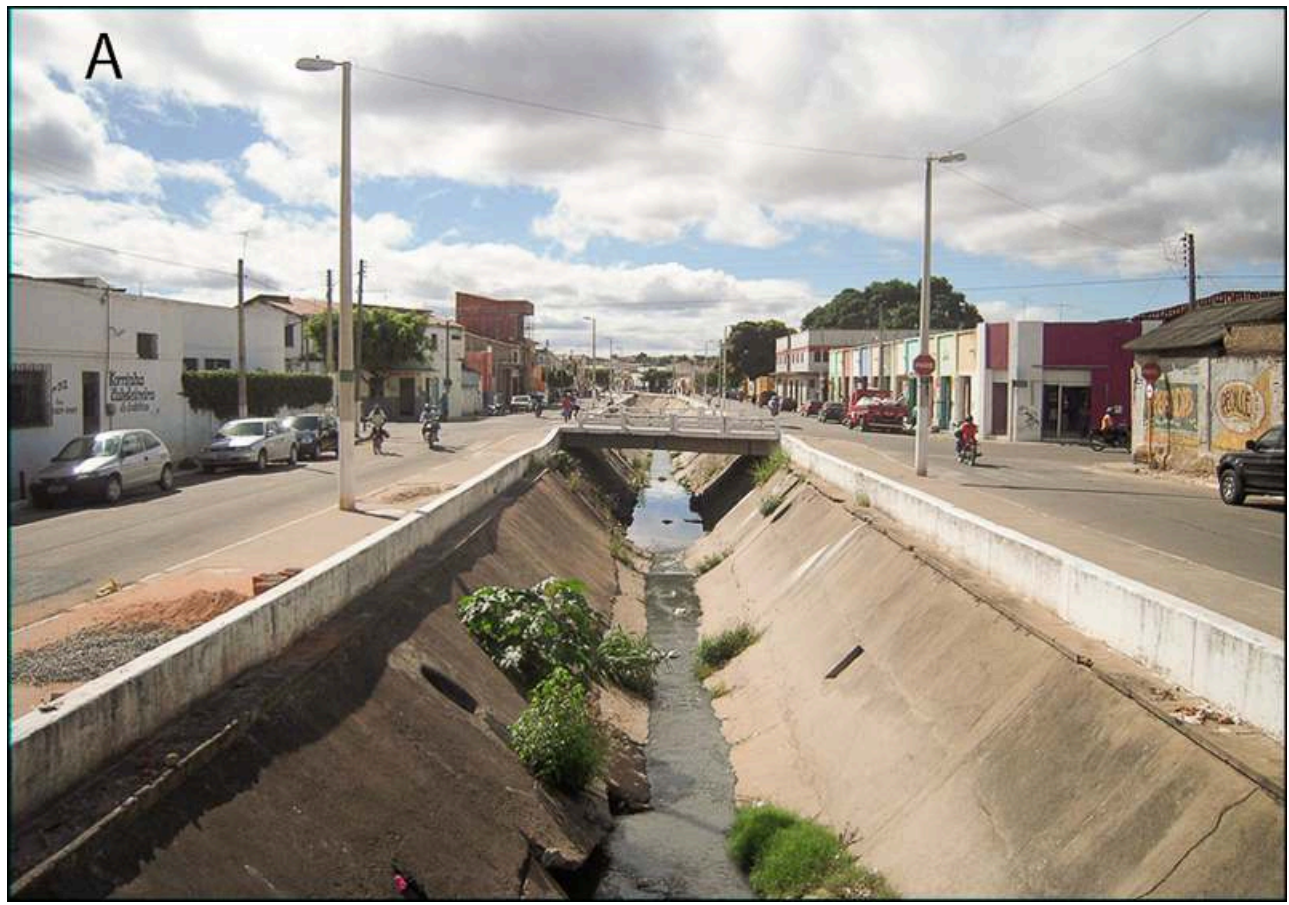

Auteur : JP. Peulvast, juillet 2010.

Illustration 8B - Le canal à l'aval du collège Objetivo, vu vers l'amont (au fond : la Chapada do Araripe)

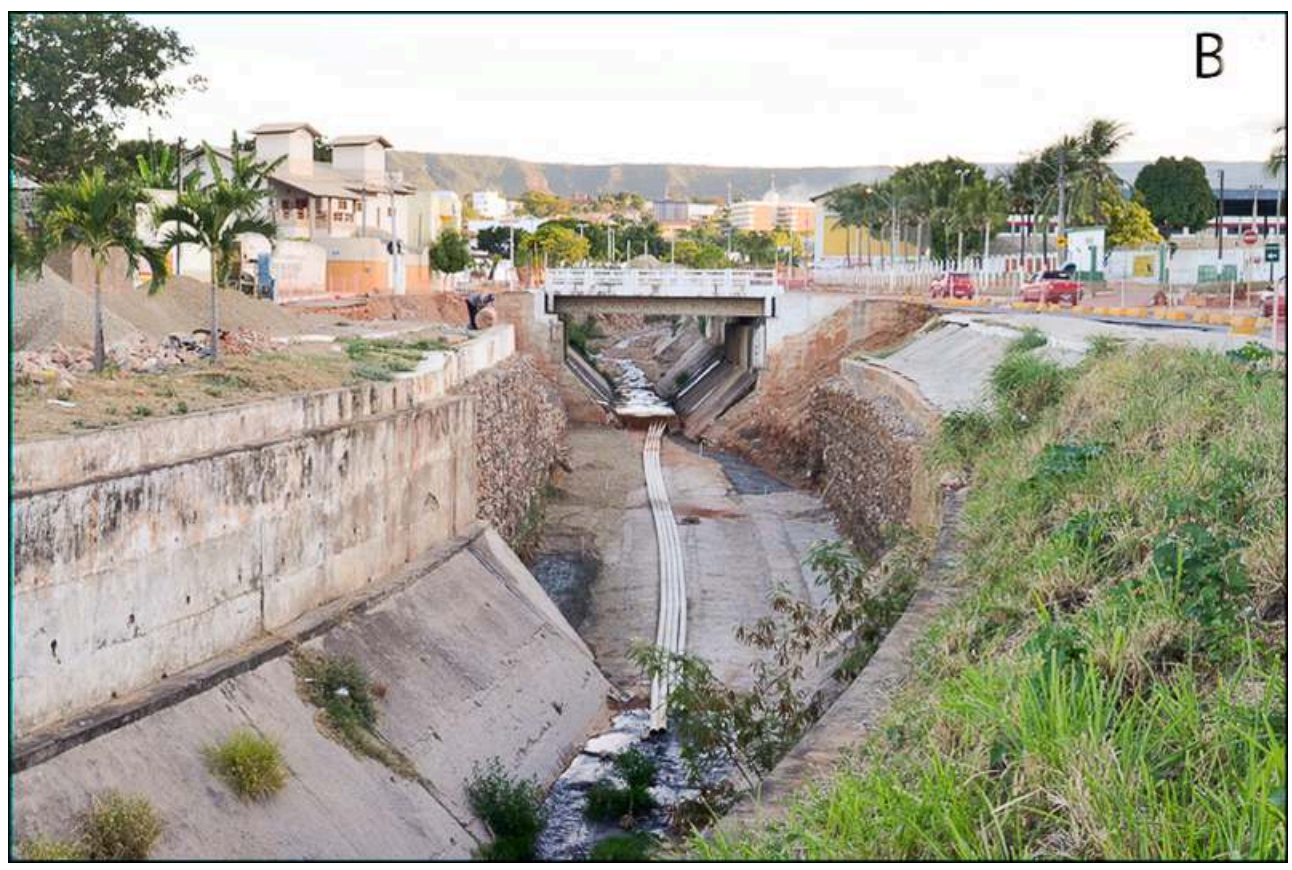

Section rétrécie (pont), photographiée en juillet 2012 après destruction et reconstruction partielles (gabions) ; la section trapézoïdale d'origine est partiellement préservée.

Auteur : JP. Peulvast, juillet 2012 
Illustration 8C - Partie amont du canal

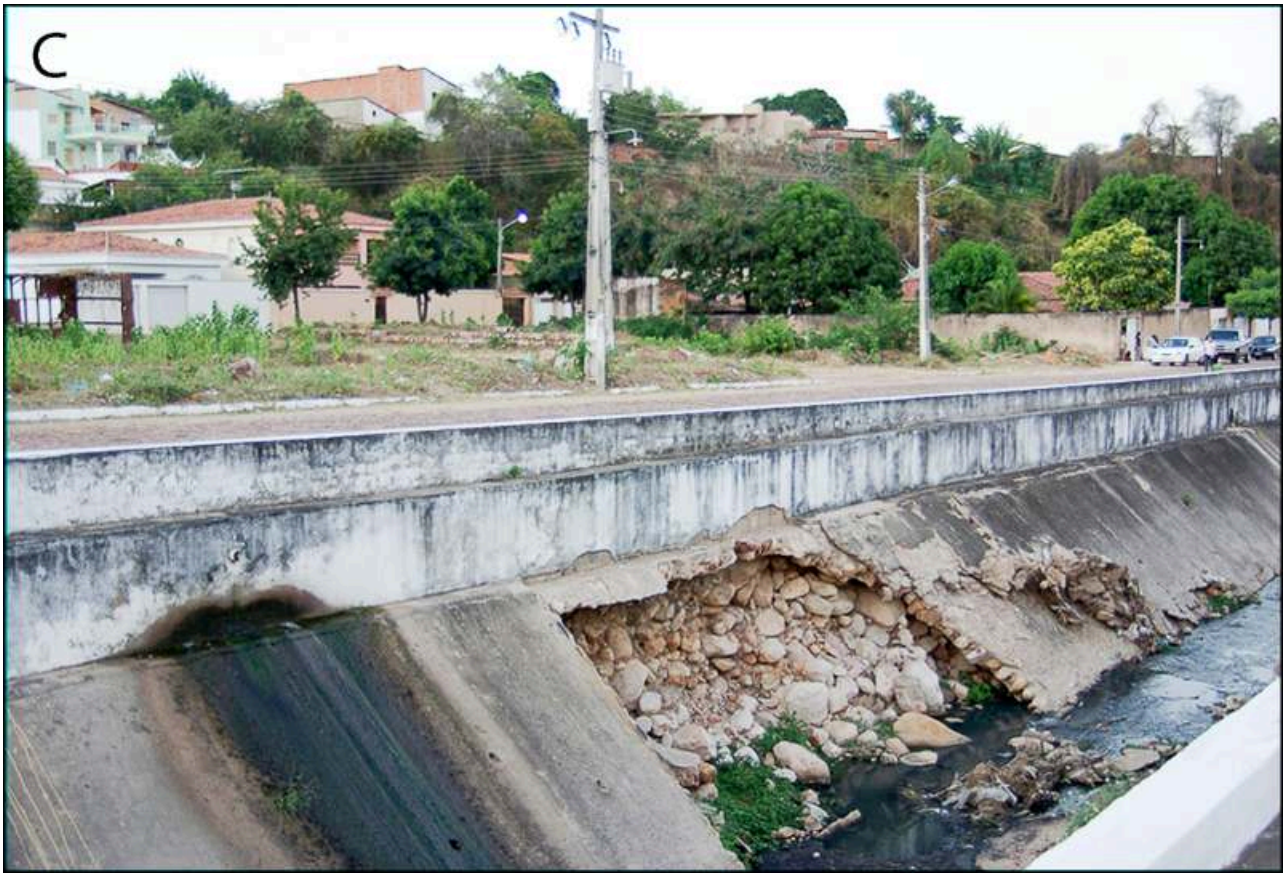

Paroi de rive gauche partiellement détruite par une crue précédente, laissant voir le matériel grossier « clast supported »de coulée de débris dans lequel le chenal d'origine est emboîté. Remarquer la minceur des plaques constituant la paroi inclinée.

Auteur: JP. Peulvast, août 2010.

Illustration 8D - Le canal en centre-ville, près de la mairie, vers l'amont

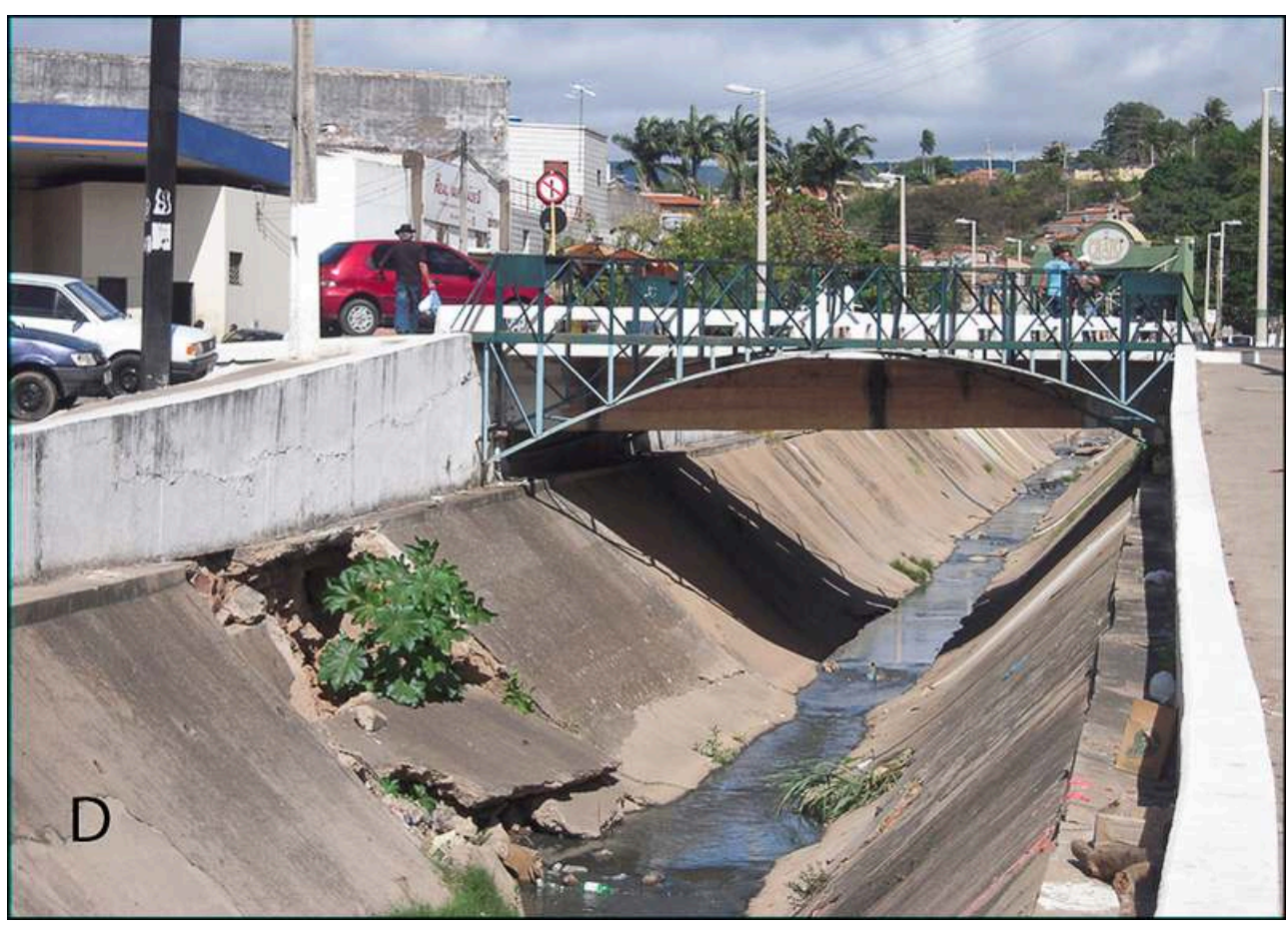

Le pont et la passerelle réduisent la section, augmentant le risque de débordement et de constitution d'embâcles. Paroi mince et dégradée (plaque de béton faiblement armée, descellée et basculée, prête à être emportée par la crue suivante)

Auteur: JP. Peulvast, juillet 2010 
Les tronçons les plus dégradés se concentrent à l'amont du débouché du ravin (voçoroca) du Seminário, c'est-à-dire dans la partie construite la plus récemment (années 2000). Des pans entiers de parois, longs de plusieurs dizaines de mètres, ont disparu en rive gauche comme en rive droite, mettant à nu le matériel grossier et hétérométrique de la terrasse ou le remblai sableux sur lequel est assis l'ouvrage là où le recoupement des courbes naturelles l'éloignait des berges (illustration 9A). Le sapement et le recul au détriment de la voirie adjacente sont maximum au débouché d'un petit affluent busé venant du quartier Pimenta, au sud, et à l'amont du rétrécissement correspondant au pont de la rue Rui Barbosa. En rive gauche, le sapement s'est dangereusement approché du mur extérieur du bâtiment principal du collège Objetivo (illustration 9B).

Illustration 9A - Le canal du Rio Grangeiro après la crue du 28 janvier 2011, segment entièrement détruit face au collège Objetivo, vers l'amont

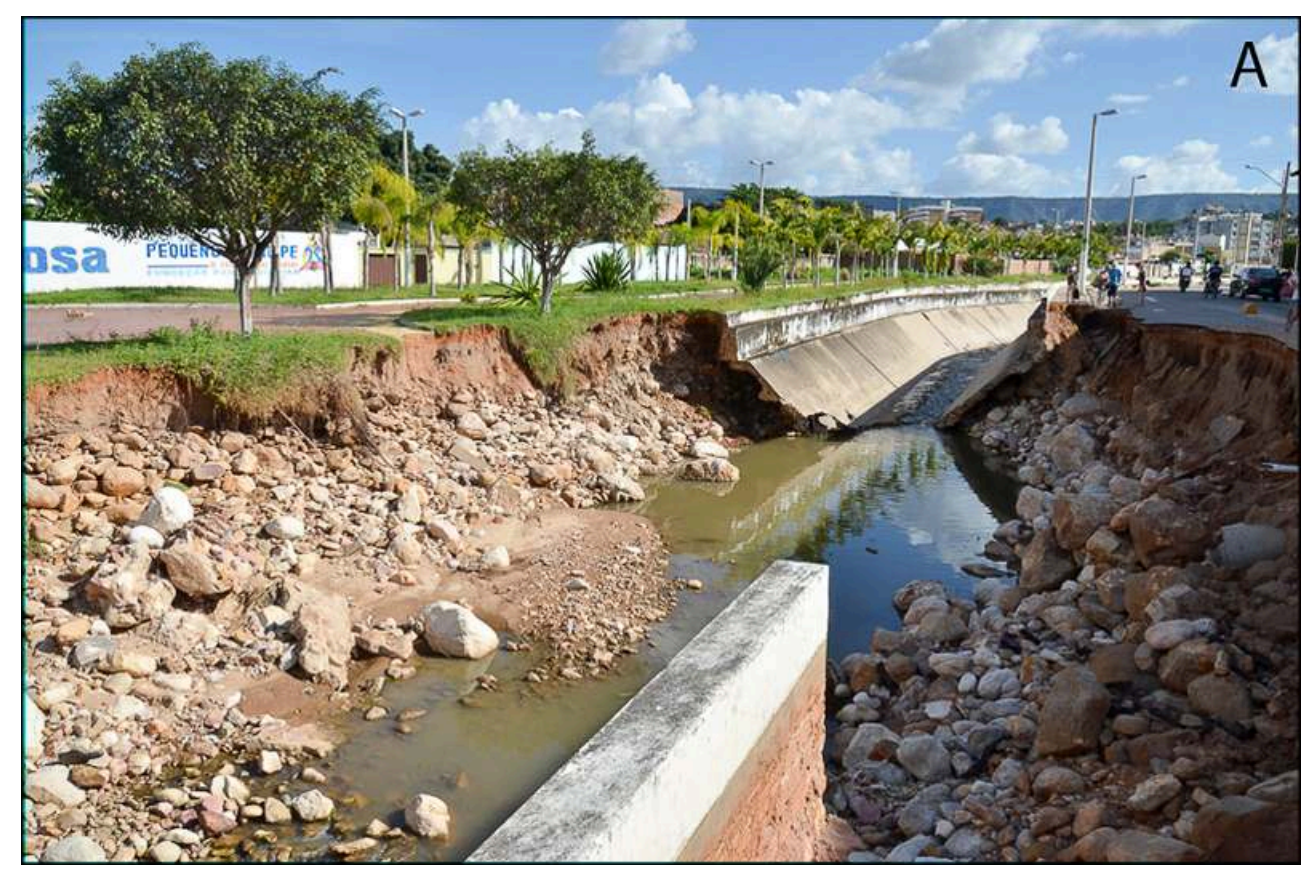

Remarquer le matériel grossier de la terrasse de coulée de débris où s'emboîte le chenal et contre lequel les parois du canal avaient été directement posées.

Auteur: JP. Peulvast, avril 2011

Illustration 9B - Le même segment, en fin de crue (28/01/2011) 


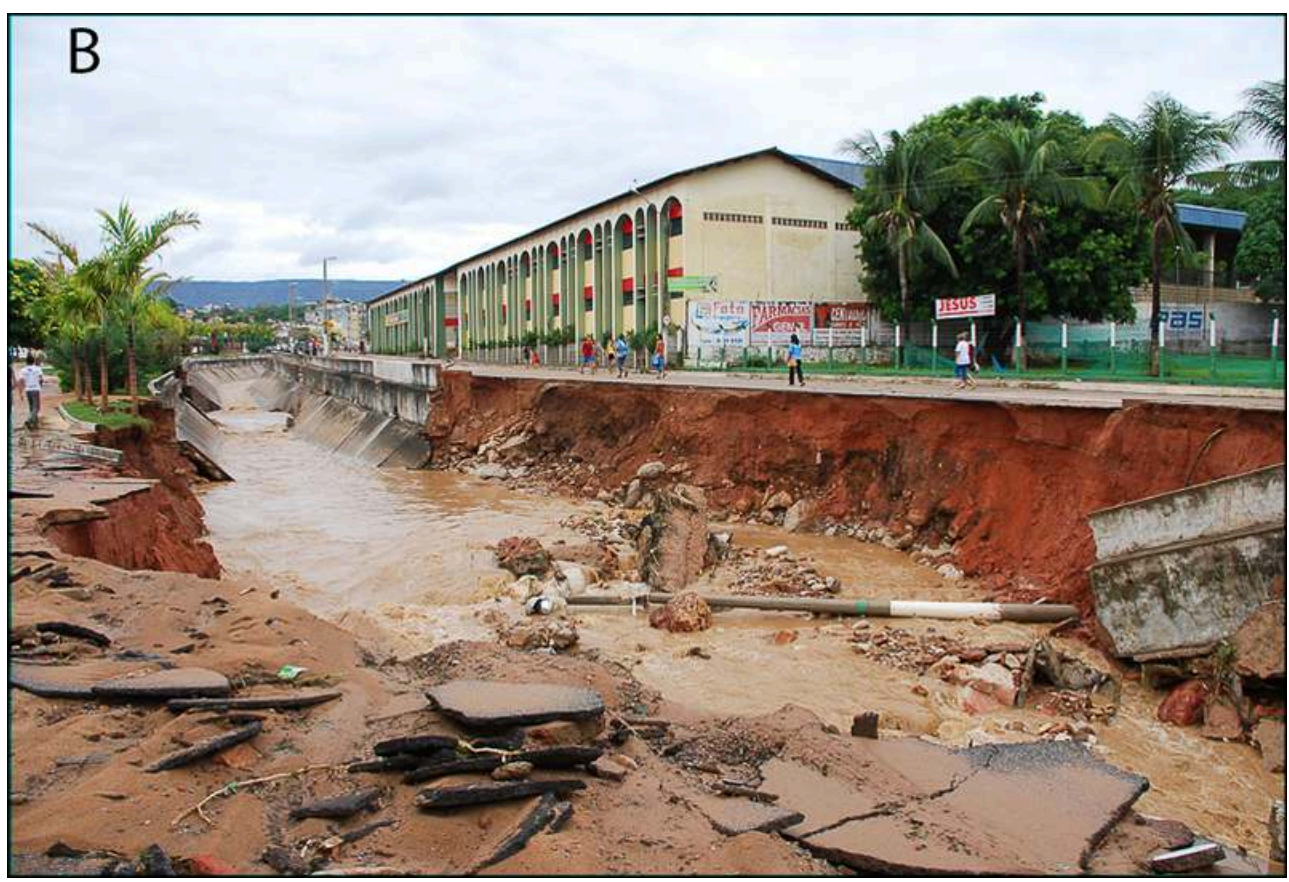

Moins avancée, la destruction sera parachevée par de petites crues ultérieures et par les travaux de nettoyage des parties fragilisées.

Auteurs : H. Maia et W. Vieira, janvier 2011.

Illustration 9C - Le canal en fin de crue $(28 / 01 / 2011)$ près du centre-ville

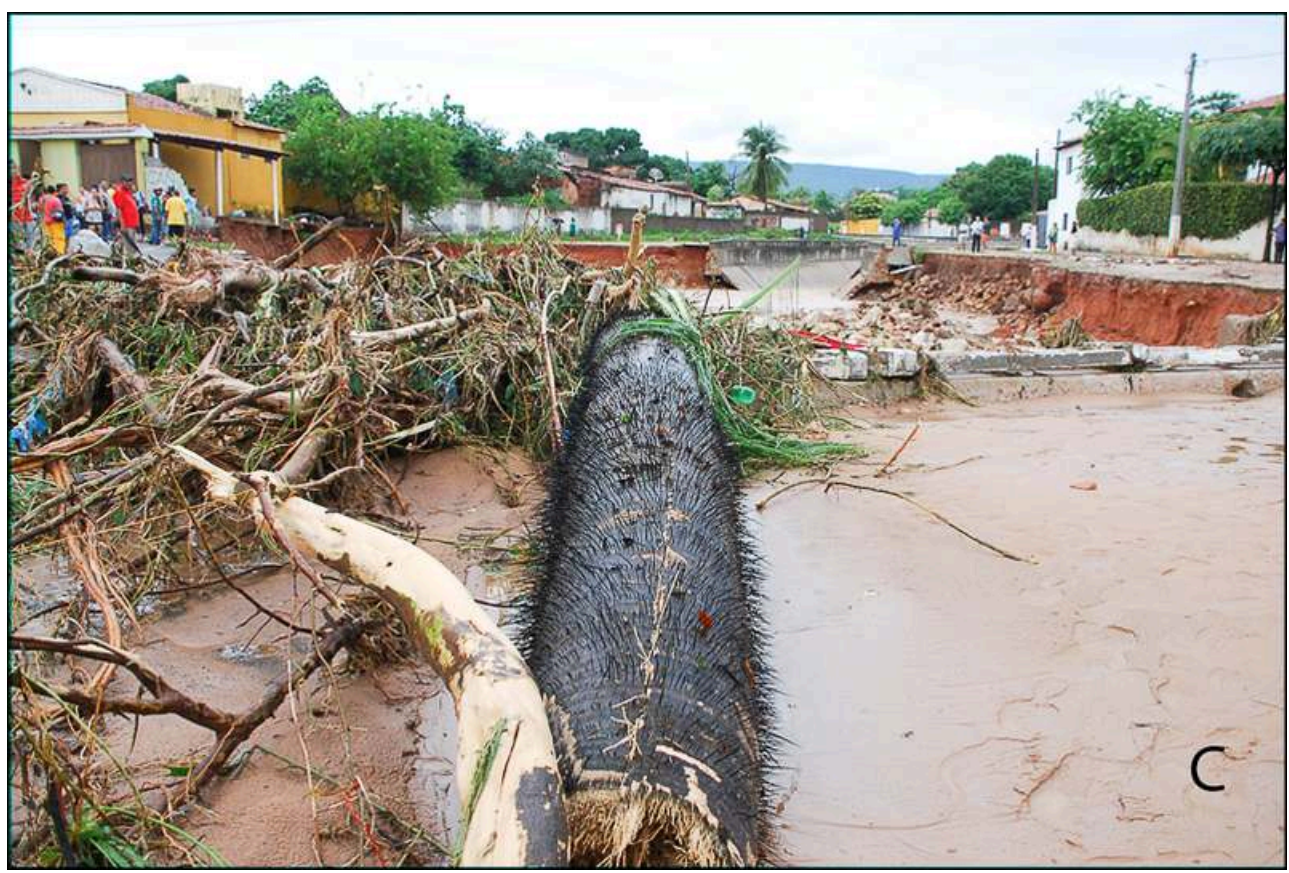

Débris végétaux rejetés en berge.

Auteurs : H. Maia et W. Vieira, janvier 2011. 
Illustration 9D - Engravement du canal détruit en amont de l'église Nossa Senhora de Fátima $(28 / 01 / 2011)$

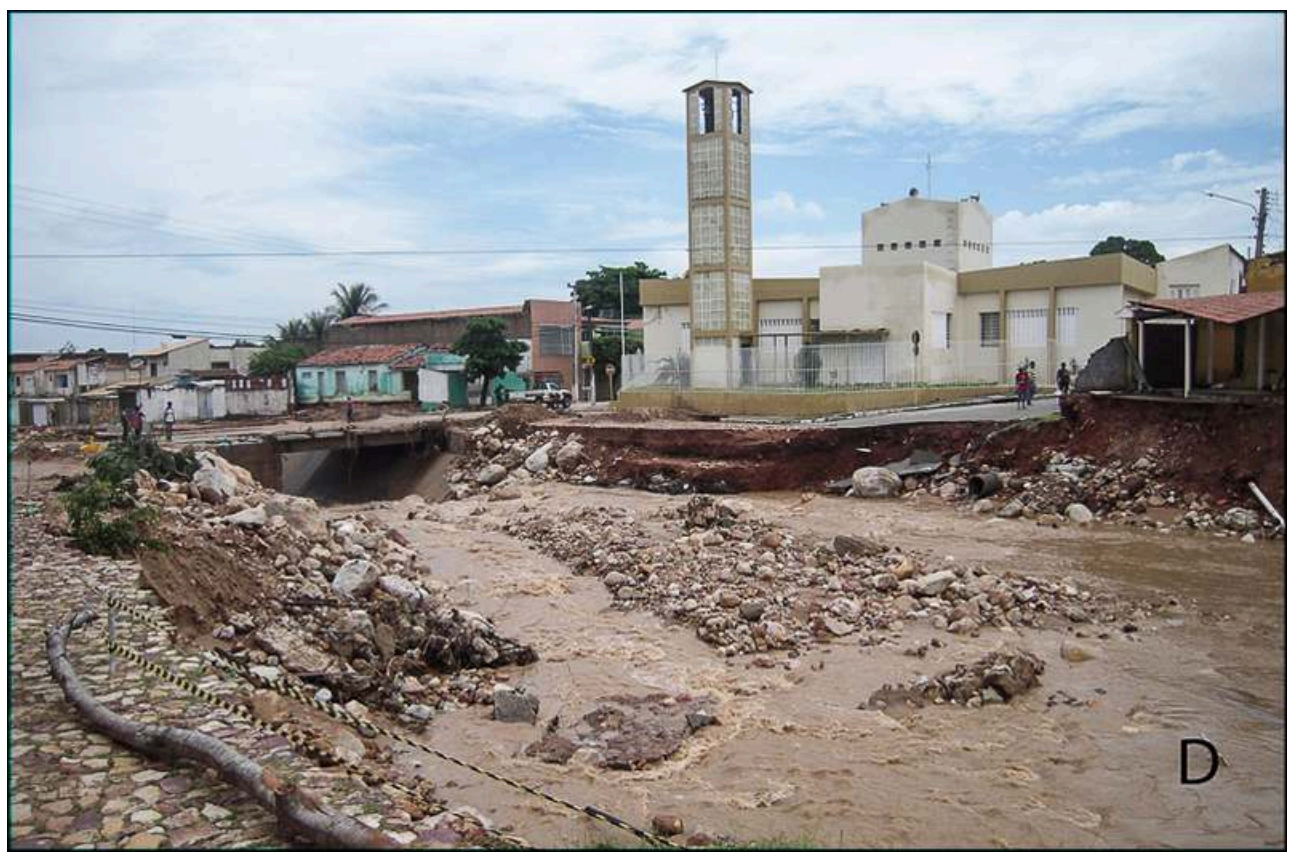

Auteur : A.O. Magalhães, janvier 2011

Les débris des ouvrages qui ont été partiellement ou totalement détruits (passerelles surtout) ont pu obstruer le chenal, au moins temporairement, de même que quelques troncs de palmiers, finalement rejetés sur les berges (illustration 9C). Plusieurs embâcles de blocs de grès et de béton ont été observés, immédiatement à l'aval des tronçons où l'eau a détruit les parois et affouillé le matériel grossier de la terrasse remis au jour (illustration 9D). Par chance, aucun véhicule n'a été emporté dans le chenal et n'a ainsi contribué à l'obstruer.

\section{Facteurs et impacts : altération du milieu naturel, urbanisation, enjeux, vulnérabilité et perception des risques}

\section{Facteurs naturels prédisposants et déclenchants : morphologie du bassin-versant, conditions de formation des crues}

Les dimensions et la forme du bassin-versant, grossièrement rectangulaire avec un étranglement à l'aval, sont favorables à un écoulement rapide des eaux issues des précipitations et à de courts temps de formation des crues. La déclivité d'ensemble, entre les sources ( $720 \mathrm{~m}$ d'altitude) et la confluence avec le Rio da Batateira (401 m) est de 3,04\% mais elle est beaucoup plus forte à l'amont de la plaine alluviale, y compris à la traversée de la ville ( $300 \mathrm{~m}$ de dénivelée sur $6500 \mathrm{~m}$, soit $4,6 \%$ ). Ne tenant pas compte des hautes parois boisées des entonnoirs surplombant les sources $(240 \mathrm{~m}$ de dénivelée supplémentaire), ces chiffres traduisent tout-de-même l'existence d'un véritable système torrentiel montagnard, au fonctionnement spasmodique. Dans la ville même, le tronçon canalisé présente une pente moyenne de 1,9\%, intermédiaire 
entre celles d'une rivière de plaine et d'un torrent. Ces valeurs sont légèrement inférieures à celles des voisins immédiats (Rio da Batateira, Riacho Saco). À l'état naturel, ceci pourrait conférer au bassin-versant un temps de concentration des eaux un peu moins court (44 minutes selon Silva, 2011a), plus favorable à l'infiltration sinon à l'évaporation donc à un amortissement des crues (Lima Neto et al, 2008). La réalité actuelle est bien différente.

Malgré un nombre élevé de drains élémentaires et d'ordres supérieurs (56 selon Ribeiro, 2004), la densité de drainage $\left(1,02 \mathrm{~km} / \mathrm{km}^{2}\right.$ selon Lima Neto et al., 2008) est assez faible, ce qui pourrait s'expliquer par la porosité du substrat et des sols. Selon le système de hiérarchisation de Horton (1945) modifié par Strahler (1957), le Rio Grangeiro devient un drain de $4{ }^{\mathrm{e}}$ ordre (ou 40 , selon la méthode cumulative de Shreve, 1966) à l'aval de Lameiro, là où il traverse Crato. Dans la partie amont du bassin-versant $\left(10,6 \mathrm{~km}^{2}\right)$, les drains élémentaires issus des sources du pied de la chapada ou nés dans des vallons déconnectés de l'escarpement (Rio das Piabas) forment un réseau plus touffu. Les rapports de confluence (ou de bifurcation) sont plus élevés ( $\mathrm{Rb}=3,72$, pour les drains de $1^{\text {er }}$ et de $2^{\mathrm{e}}$ ordres et $\mathrm{Rb}=3,67$ pour ceux de $2^{\mathrm{e}}$ et $3^{\mathrm{e}}$ ordres) que ceux de la partie aval du bassin-versant, plus resserrée et moins disséquée $\left(\mathrm{Rb}=3\right.$ entre ceux de $3^{\mathrm{e}}$ et $4^{\mathrm{e}}$ ordres). Le coefficient de compacité de cette partie du bassin-versant (rapport entre son périmètre et la circonférence d'un cercle de même superficie) est de 1,1, ce qui, là encore, est propice à la formation rapide de crues (Silva, 2011a). Il en est de même pour le coefficient de forme (rapport entre largeur moyenne du bassin-versant et longueur axiale), très élevé $(2,53)$.

31 Les cours d'eau sont normalement alimentés par plusieurs sources issues de l'aquifère supérieur (grès Exu), au contact des grès argileux sous-jacents de la formation Arajara (Grangeiro). Issue de circulations de type karstique au sein de la Chapada, l'eau peut aussi jaillir au sein de volumineuses masses glissées préservées au pied de l'escarpement (Belmonte). Il en ressort aussi dans le plancher du vallon du Riacho das Piabas, à l'aval du coude de capture qui prive le Rio Grangeiro des eaux des grosses sources qui alimentent maintenant le Rio da Batateira (illustration 2). Ces sources participent très peu au fonctionnement actuel des cours d'eau, étant pratiquement toutes captées. Hors saison des pluies, tous les drains sont pratiquement à sec ou seulement parcourus par de maigres filets d'eau. En ville, seules s'écoulent des eaux usées et nauséabondes qui se déversent librement dans le chenal. Ainsi, aucune mesure des débits de base n'est disponible.

Ce sont donc principalement les eaux provenant directement des précipitations et celles des nappes temporaires constituées dans les sols du bassin-versant, qui participent à la constitution des épisodes d'écoulement, souvent brefs et brutaux, caractéristiques $\mathrm{du}$ fonctionnement du système. Selon Ribeiro (2004), les eaux superficielles parcourent en moyenne $236 \mathrm{~m}$ dans les versants pour atteindre un drain. Compte tenu des pentes des versants et des talwegs (pourtant inférieures à celles des bassins-versants voisins selon Lima Neto et al., 2008), le ruissellement de surface (écoulement hortonien), lié à un dépassement de la capacité d'infiltration des sols, entraîne une réponse très rapide des cours d'eau (" écoulement rapide de crue", Bravard \& Petit, 1997). Il dépend beaucoup de l'état et du degré de couverture des sols (végétation, constructions et revêtements divers...). Un écoulement de surface saturée s'y ajoute si l'épisode pluvieux se prolonge et/ou s'il succède à d'autres épisodes. Dans ce dernier cas, même des précipitations modestes peuvent déclencher un écoulement 
rapide de crue. Il est donc important de connaître aussi bien les caractéristiques du substrat et des sols que celles des précipitations impliquées dans chaque événement.

L'escarpement d'où vient le Rio Grangeiro est façonné dans les couches supérieures de la série mésozoïque qui occupe la partie orientale du bassin Araripe (Peulvast et al., 2011). Cette série sub-horizontale, d'âge Aptien supérieur à Cénomanien, comporte $250-280 \mathrm{~m}$ de roches tendres coiffées par des grès massifs, résistants et poreux (150-250 m) qui forment la corniche supérieure de l'escarpement. La concavité basale et les glacis disséqués sont respectivement sculptés dans des grès argileux (Formation Arajara) et dans les roches généralement peu résistantes des Formations Santana et da Batateira. En dehors de la dalle de grès sommitale et des calcaires, qui forment les deux aquifères susceptibles d'alimenter les sources et de soutenir un débit de base (CPRM, 2005), cette série est globalement peu perméable, voire très imperméable (niveaux argileux) et donc potentiellement favorable à la constitution de ruissellements superficiels.

En réalité, du fait de la présence de fortes couvertures colluviales et alluviales (masses glissées, couvertures de glacis, terrasses), le substrat affleure peu dans le bassinversant. Ce sont surtout les formations superficielles qui conditionnent la capacité d'infiltration de l'eau. Les dépôts caillouteux ou sableux qui tapissent le fond des chenaux et forment les terrasses sont très perméables, mais ce sont précisément les terrasses, constituées de dépôts très grossiers de coulées de débris dans la ville de Crato (illustration 8C), qui sont urbanisées et partiellement imperméabilisées. Ailleurs, l'altération, conduisant à la formation de sols argileux et de remplissages argileux le long des fissures des roches, est très importante dans l'environnement initialement forestier de la région. Des altérites et des sols riches en kaolinite (ferralsols), atteignant jusqu'à $10 \mathrm{~m}$ d'épaisseur, revêtent les grès altérés (Bétard, 2007). Des manteaux d'altération plus minces (lixisols, leptosols) sont visibles dans les versants et sur les croupes d'interfluves du piémont. Ces sols poreux existent aussi à la base de l'escarpement et dans ses entonnoirs de sapement. Ils sont prédominants dans les systèmes de glacis disséqués. Tous sont sensibles au ravinement et aux glissements de terrain de petite taille (Ribeiro, 2004), phénomènes producteurs de boue qui contribuent au débit solide entraîné lors des crues, à la viscosité des écoulements et à leur capacité d'emport d'éléments grossiers.

Ces indications confirment celles de Sousa et al. (2006), selon lesquels les facteurs naturels prédisposent déjà le Rio Grangeiro et ses affluents à des comportements dangereux. Le contraste brutal entre les fortes pentes longitudinales des talwegs à l'amont, favorables à des vitesses d'écoulement élevées, et les pentes plus faibles dans ce qui constituait, avant urbanisation, une plaine d'inondation plus large, y favorise une tendance au ralentissement et à l'étalement latéral. La situation du centre-ville à l'articulation des deux secteurs peut donc par elle-même constituer un facteur de risque, d'autant plus que c'est précisément à cet endroit que le cours d'eau se trouve confiné dans un canal de béton à profil trapézoïdal (illustration 8A). D'un modèle classique au Brésil (ex : São Paulo, Rio Tiete) comme aux États-Unis (ex : Los Angeles), ce canal construit à partir de 1957 (premier tronçon: Seminário-mairie) s'est révélé trop étroit et propice aux débordements. En outre, il reçoit des eaux transposées depuis les sources du Rio da Batateira (Sousa et al., 2006). 


\section{Facteurs aggravants}

La population et les autorités sont confrontées aux effets d'un empiètement incontrôlé sur un lit fluvial qui devrait pourtant, selon la législation brésilienne, constituer une aire de préservation permanente (Résolution du Conselho Nacional do Meio Ambiente CONAMA, $\mathrm{n}^{\mathrm{0}} 303$, article 3 , 2002). Par analogie avec la morphologie de rivières voisines aux caractéristiques proches (Rio Salamanca ; illustration 10A), et comme le confirment quelques photos anciennes (illustration 10B), il se présentait comme une étroite bande de tressage large de quelques dizaines de mètres au plus, entre des berges creusées dans une basse terrasse riche en gros blocs de grès. Sur deux kilomètres, l'écoulement, transformé en puissant torrent le temps d'une très grosse pluie, ne dispose d'aucune zone d'expansion. Il est au contraire entravé par des réductions de section (rétrécissements, ponts trop bas) qui l'amènent à déborder, surtout en cas de formation d'embâcles (débris végétaux ou artificiels, véhicules) (illustration 8B, illustration 11A). La montée des eaux est telle que les buses adventices sont engorgées et l'eau fait éclater les conduites, soulève les plaques de regard et ressort dans d'autres rues du centre-ville (Riacho da Vala).

Illustration 10A - Lits fluviaux «naturels » sur le piémont NE de la Chapada do Araripe : le Rio Salamanca à Cabaceira (Barbalha)

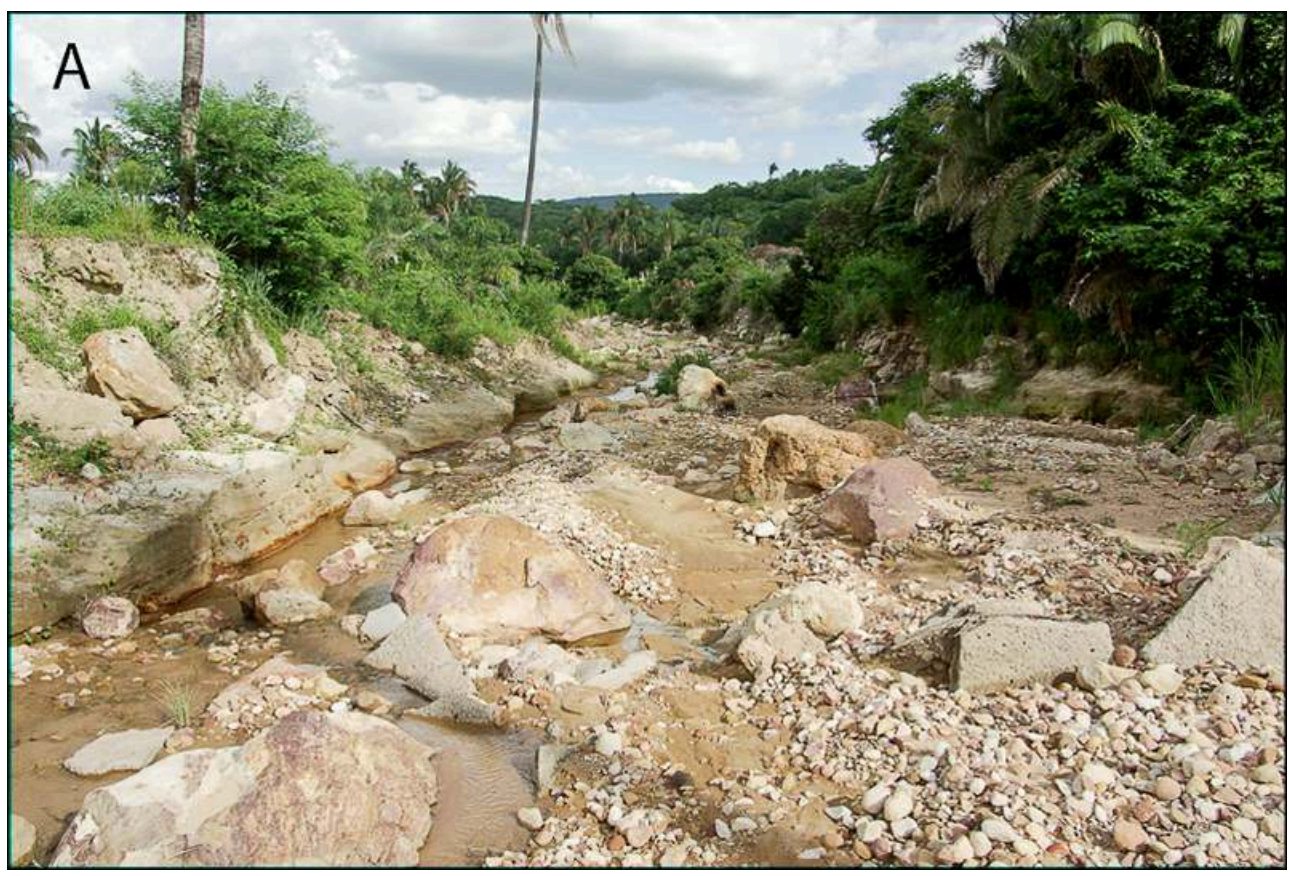

Auteur: JP. Peulvast. 
Illustration 10B - Le Rio Grangeiro à Crato (quartier Pimenta) avant artificialisation (2003)

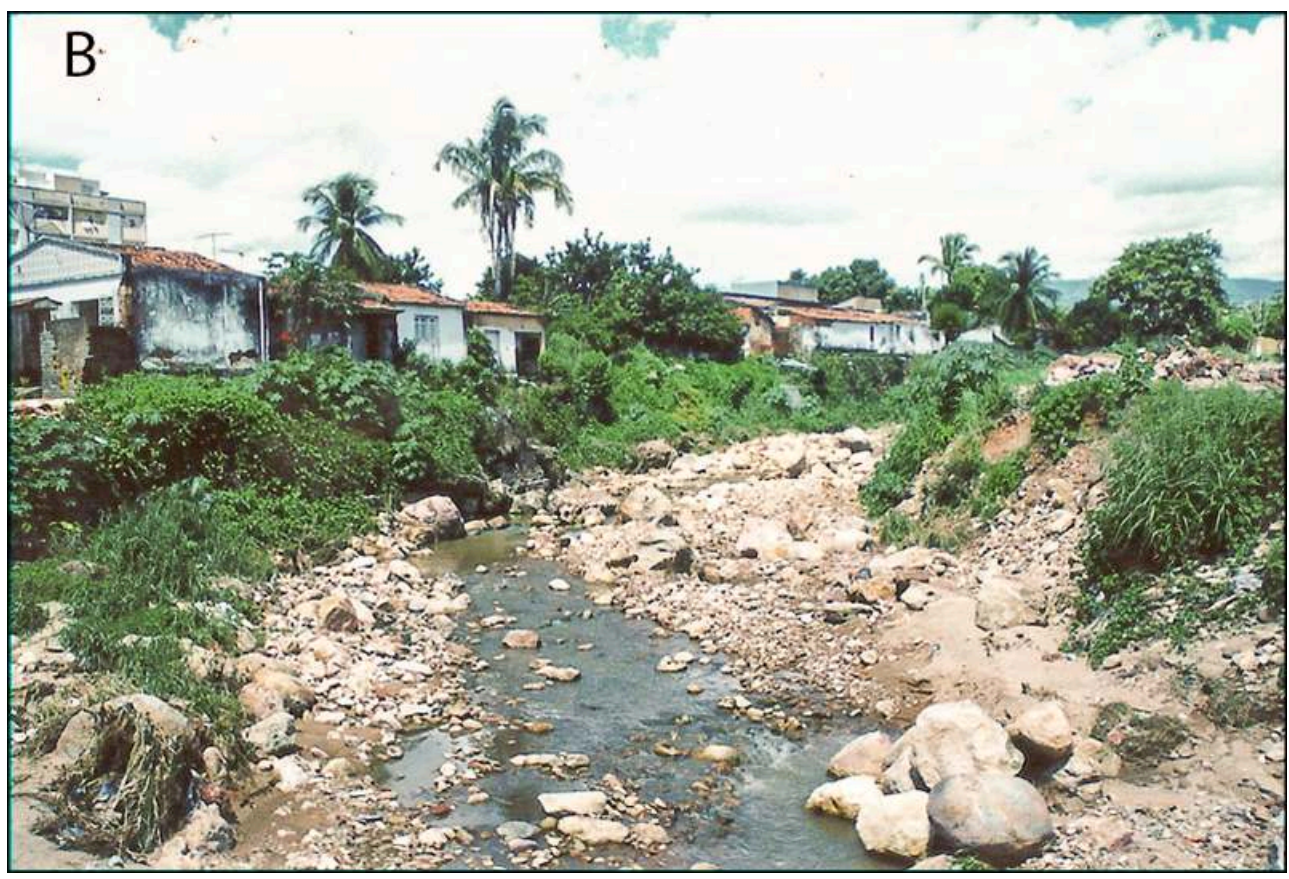

Auteur : A.O. Magalhães.

Illustration 11A - Ecoulements de fin de crue et embâcles dans le Rio Granjeiro : passerelle détruite et partiellement emportée, centre-ville $(28 / 01 / 2011)$

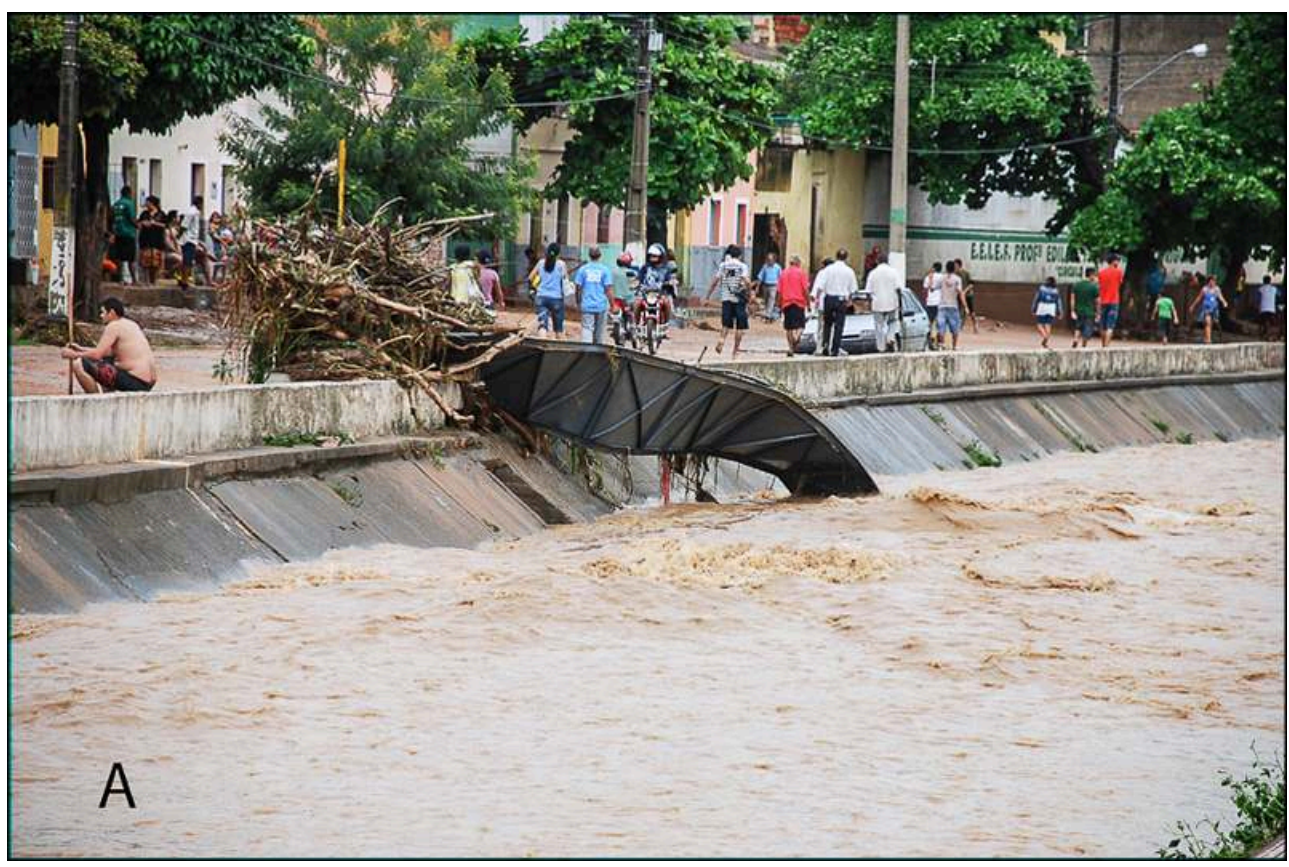

Auteurs : H. Maia et W. Vieira 
Illustration 11B - Ecoulement turbulent et embâcle de blocs de béton, aval de l'église Nossa Senhora de Fátima $(28 / 01 / 2011)$

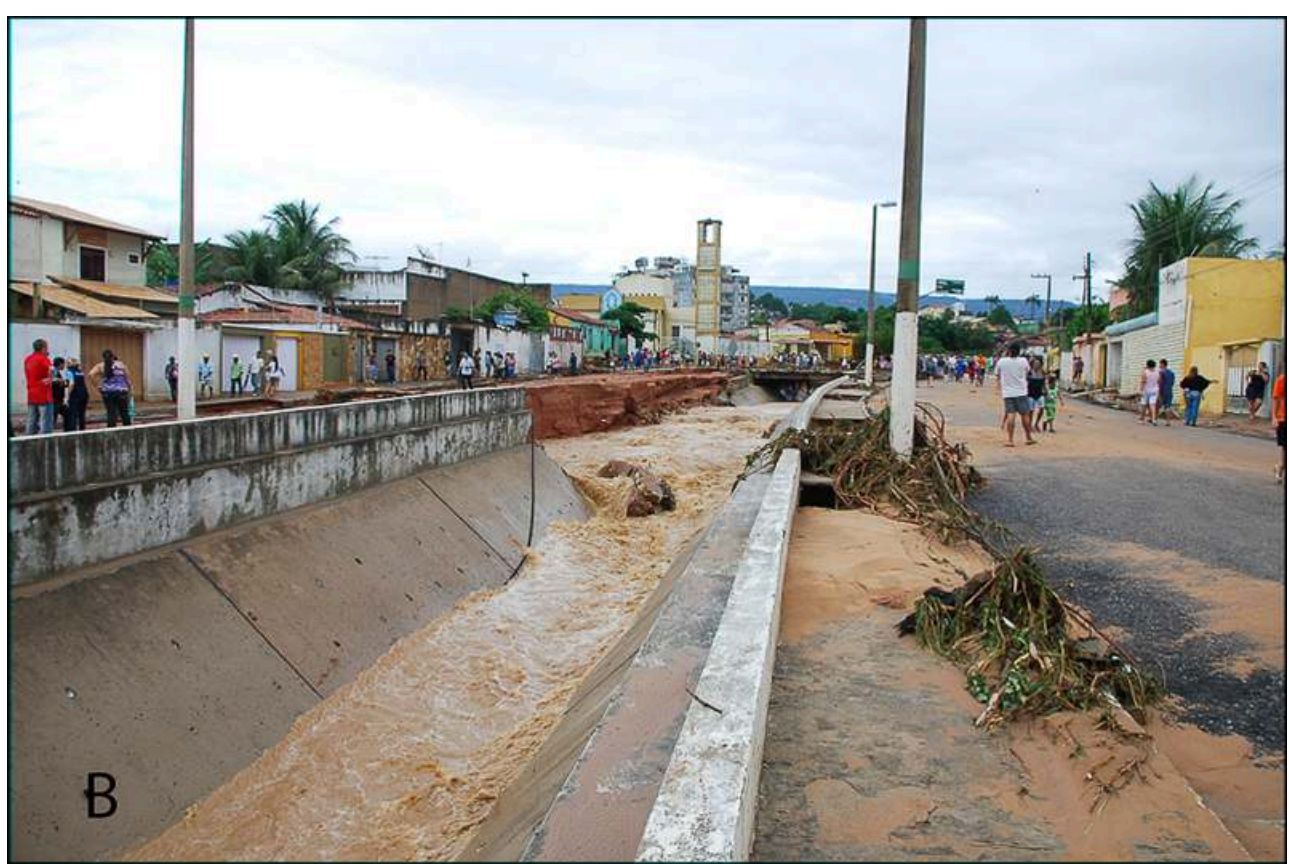

Auteurs : H. Maia et W. Vieira.

Les rapports techniques rédigés après la crue (Oliveira, 2011; Silva, 2011a, 2011b) soulignent les nombreux défauts du chenal bétonné. Parmi eux, de nombreux branchements de canalisations d'eaux pluviales et usées ou même d'affluents busés (Riacho da Vala, voçoroca de Seminario-Vulcão) arrivant selon un angle de l'ordre de $90^{\circ}$ et construits avec des matériaux de qualité inadéquate (briques communes), sans augmentation de section à l'aval. Le rapport signale aussi l'encombrement du chenal, avant la crue, par des sables et des matériaux naturels (blocs de grès) ou artificiels (gravats, morceaux de parois...), susceptibles d'accroître les perturbations et la turbulence de l'écoulement, de faire barrage ou même de se comporter en véritables béliers quand la force de l'eau les entraîne contre les parois (illustration $8 \mathrm{D}$ ). Une partie de ces apports est attribuée à une augmentation de l'érosion à l'amont, liée à des actions de déboisement et à des constructions irrégulières dans l'Aire de Protection Environnementale (APA Chapada do Araripe) qui englobe le pied de l'escarpement. Sont accusés aussi les ouvrages en déblai avec des pentes supérieures à $45^{\circ}$, restés sans protection végétale.

Plus grave, la configuration même du chenal, avec sa section insuffisante, son profil transversal et son rapport profondeur/largeur variables (illustration 8B), accompagnés de ruptures de pente reflétant sa construction en plusieurs étapes, ses courbes ou ses coudes brusques et ses rétrécissements surtout adaptés aux impératifs de l'établissement des voies adjacentes (une avenue de chaque côté, des ponts de différentes longueurs et hauteurs par rapport au fond), est mise en cause : «il ne semble pas exister d'études hydrologiques de détail qui auraient pu permettre cette configuration » (traduit de Oliveira, 2011). Cet avis est confirmé par Silva (2011b), selon lequel le chenal, avec sa pente de 2,64 à $2,87 \%$, a été construit de façon à permettre un écoulement supercritique très turbulent et à haute énergie (illustration $11 \mathrm{~B}$ ), alors que l'écoulement sous-critique qui est la norme pour les chenaux fluviaux artificialisés 
requiert une pente de 0,010 à $0,015 \%$. Il n'existe en outre aucune structure hydraulique de dissipation de l'énergie. La vitesse d'écoulement lors de la crue du 28 janvier 2011 y a été évaluée à $11 \mathrm{~m} / \mathrm{s}$, alors qu'elle ne devrait en aucun cas dépasser $6 \mathrm{~m} / \mathrm{s}$ dans un chenal en béton (Silva, 2011b).

L'état déjà alarmant du canal avant la crue, régulièrement dénoncé par les journaux locaux depuis 2008, a contribué à aggraver les destructions (illustration 8C, illustration $8 \mathrm{D}$ ). Les habitants interrogés redoutaient depuis longtemps les effets de l'absence d'entretien d'un ouvrage aux parois minces et de piètre qualité, surtout dans sa moitié amont (plaques de béton minces, faiblement armées et mal jointées), de la disparition dès 2010 de pans entiers de ces parois, mettant au jour les dépôts hétérométriques et peu cohérents de coulées de débris sur lesquels s'assoit directement l'ouvrage, des marques de suffosion visibles sous les trottoirs voisins, ou encore de la multiplication anarchique des branchements d'égouts et d'eaux pluviales, souvent brisés. Parmi les rapports techniques, seul celui de Silva (2011b) prend en compte l'état du lit à l'amont du chenal. Ici, à l'exception d'un court tronçon de chenal naturel entaillé sur 1 à $2 \mathrm{~m}$ de profondeur dans les grès tendres du substrat sous le pont de Lameiro (lequel voit une de ses piles dangereusement déstabilisée par suite de l'érosion active), le ruisseau serpente entre des blocs métriques et sape la terrasse dans les rives concaves de méandres (illustrations 12A et 12B). Ces dépôts anciens de coulées de débris ou de laves torrentielles, décrits par Peulvast et al. (2011) sont particulièrement spectaculaires à l'amont immédiat du chenal ; ils constituent une réserve de matériaux susceptibles de venir l'obstruer en cas de mobilisation par les crues les plus violentes (illustration $12 \mathrm{C}$ ). Le rôle des blocs de grès omniprésents dans le site urbain (Peulvast et al, 2011) est généralement négligé car la pratique courante et incontrôlée consistant à les fragmenter en pavés pour l'empierrement dès qu'ils sont mis au jour fait rapidement disparaître les plus encombrants d'entre eux. Elle modifie aussi la composition de la charge sédimentaire pour les crues suivantes, dont la capacité de transport et le rôle érosif sont amplifiés. 
Illustration 12A - Le Rio Grangeiro à l'amont du canal : aval du pont de Lameiro

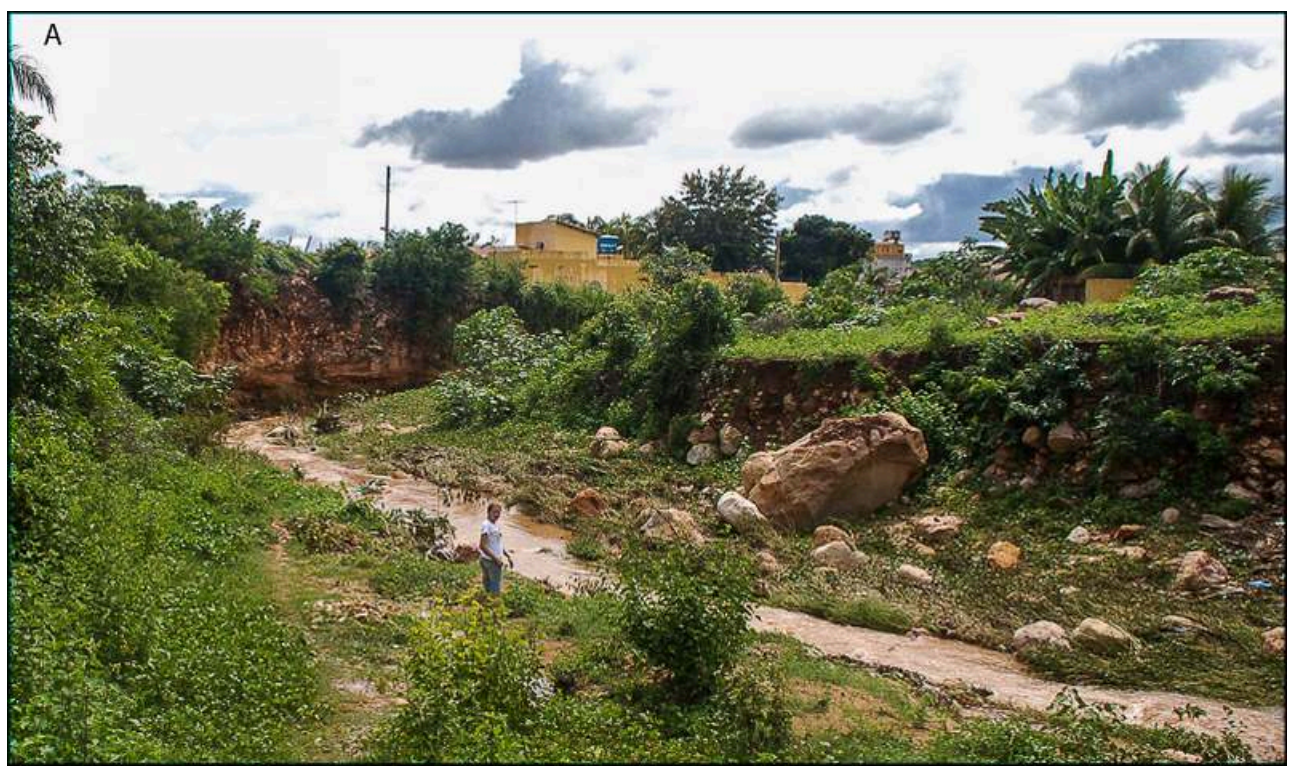

Coupes dans l'épaisse terrasse de coulée de débris qui se poursuit jusqu'au centre-ville et dans son substrat de grès tendres (Formation Rio da Batateira). Le plus gros bloc dépasse $5 \mathrm{~m}$ de longueur. Auteur: JP. Peulvast.

Illustration 12B - Sapement d'une des piles du pont de Lameiro

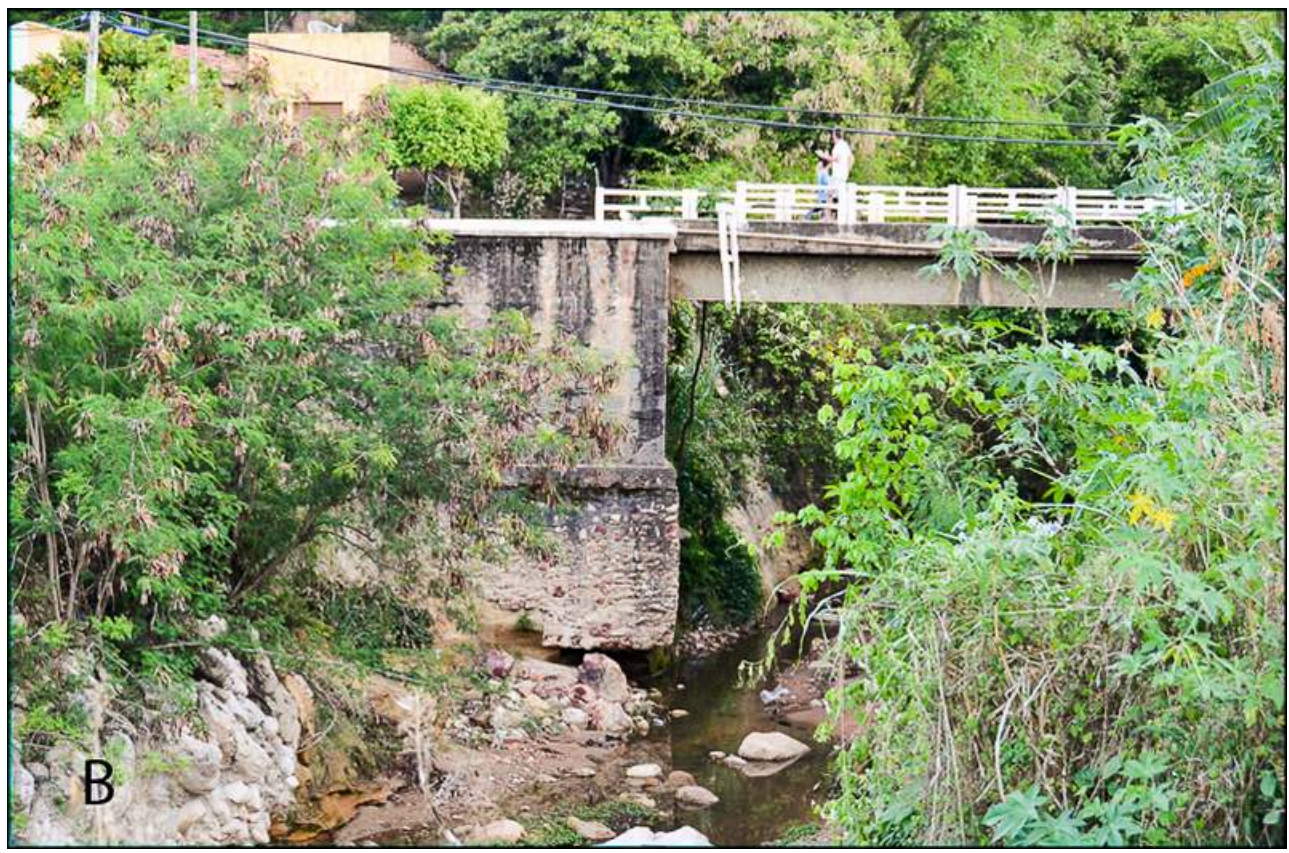

Auteur : JP. Peulvast. 
Illustration 12C - Entrée amont du canal (août 2011)

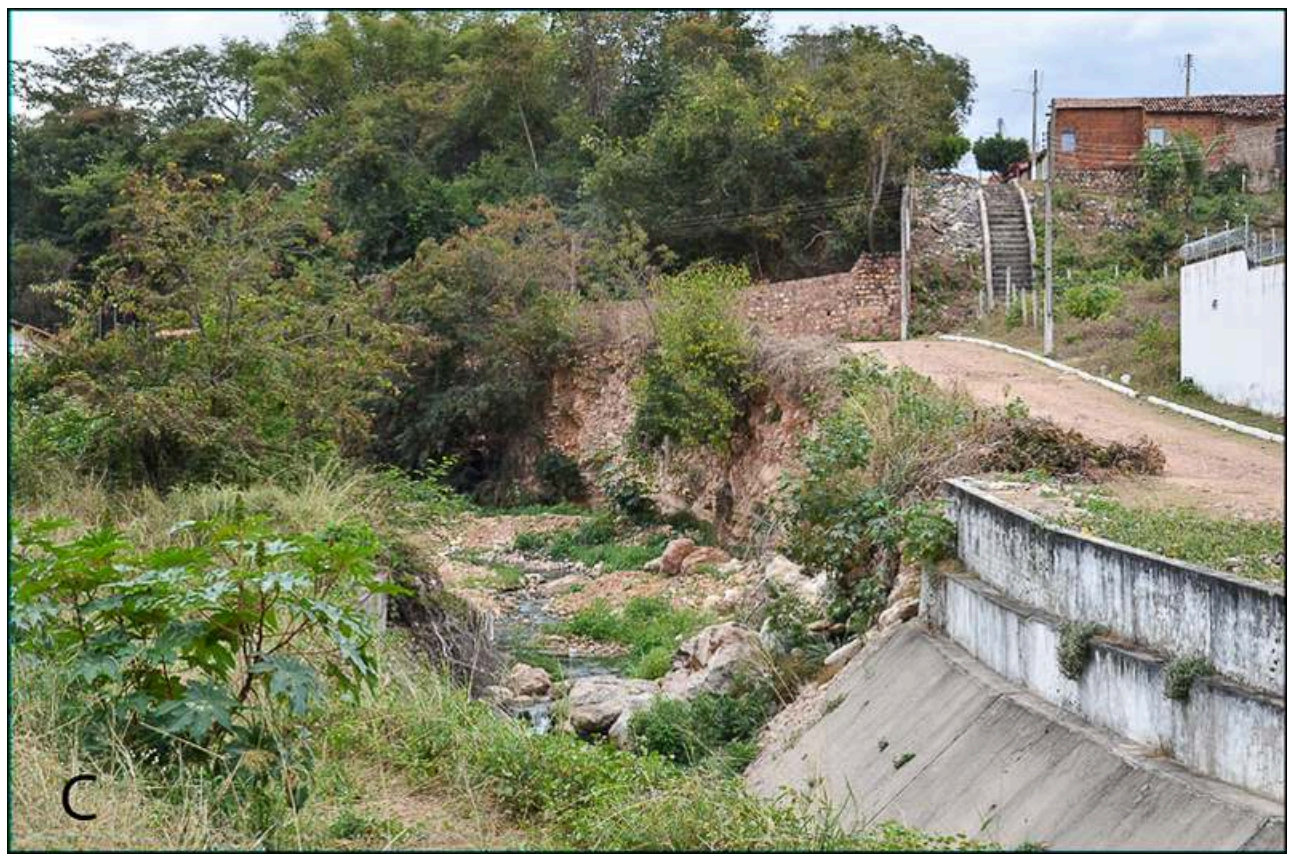

Matériaux prêts à être mobilisés par les crues suivantes.

Auteur: JP. Peulvast.

Quant aux caractéristiques du bassin-versant (réalité des déboisements, taux de couverture et d'imperméabilisation des sols, rôle de la voirie), elles restent jusqu'alors mal étudiées et devront faire l'objet, comme le mentionne le rapport de Sousa et al. (2006), d'investigations plus détaillées, en particulier par l'analyse d'images diachroniques. Parmi les facteurs anthropiques, l'importance des déboisements dans l'escarpement et son piémont, et la destruction de la forêt ripicole (mata ciliar) le long des cours d'eau, seraient responsables de ravinements et de mouvements de terrain ainsi que de l'ensablement des fonds de vallées à l'aval. Par ailleurs, le rejet des eaux usées et de résidus solides dans les chenaux non seulement cause une grave pollution mais aussi perturbe le fonctionnement hydrologique.

\section{Urbanisation et vulnérabilité}

\section{Une urbanisation récente incontrôlée}

Le centre historique de Crato a été construit dans l'étroite plaine de confluence entre le Rio Granjeiro et le Riacho da Vala (illustration 7). Ce secteur a été occupé initialement au XVIII ${ }^{e}$ siècle, avec la construction d'une petite chapelle dans un village indigène. Au XIX ${ }^{e}$ siècle, l'expansion urbaine s'est produite le long du Rio Granjeiro avec la création des quartiers Seminário, sur l'interfluve Granjeiro - Batateira, et Alto da Penha et Pinto Madeira, sur l'interfluve Granjeiro - Riacho Saco Lobo. Dans la première moitié du $\mathrm{XX}^{\mathrm{e}}$ siècle, sont construits les quartiers Pimenta, sur les terrasses fluviales qui s'élargissent progressivement vers l'aval, et Santa Luzia, en marge droite de la plaine de confluence Granjeiro-Saco Lobo (PDM Crato - Plano Diretor Municipal, 2009).

Dans les décennies 1950-1960, l'urbanisation gagne des secteurs plus éloignés du centre, avec la construction des quartiers Batateira, Misericórdia, Independência et Vila Alta 
sur les hautes terrasses de la rive gauche et du Rio da Batateira (illustration 2). Dans le même temps, la marge droite du Granjeiro et l'extrémité de l'interfluve Granjeiro-Saco Lobo sont occupées (quartiers Ossian Araripe et Sossego), ainsi que l'interfluve Saco Lobo - Constantino (quartiers São Miguel et Parque Real Mirandão). La spéculation immobilière et la construction s'intensifient dans les décennies 1970-1980, vers l'amont. Elle gagne les marges de l'Aire de Protection Environnementale (Area de Proteção Ambiental, APA Chapada do Araripe) qui englobe la partie NE de la Chapada, l'escarpement et les sources (Clube Grangeiro...). Le quartier Parque Granjeiro, constitué de lotissements, s'étale principalement sur le versant de rive droite entre le quartier Pimenta et le pied de l'escarpement, mais le réseau de rues et les constructions occupent également le fond de la vallée, avec un quadrillage de rues perpendiculaires, parallèles ou obliques par rapport au cours d'eau.

Plus récemment (décennies 1990-2010), les constructions se sont densifiées dans le bassin-versant, avec la multiplication des lotissements, des domaines résidentiels fermés (condomínios fechados), etc. Ces nouveaux ensembles sont implantés sur les glacis et les versants, généralement hors des zones inondables, mais ils contribuent à aggraver les risques dans le centre, par suite de l'imperméabilisation croissante des sols et du rôle de la voirie qui achemine plus rapidement les eaux vers les talwegs, dès que les axes sont parallèles à la pente ou suivent des talwegs (quartiers Pimenta, Sossego,Seminário).

\section{Vulnérabilité socio-environnementale, conséquences humaines et acteurs impliqués}

Selon la notification préliminaire d'état de catastrophe publiée par la Coordenadoria Estadual de Defesa Civil-CEDEC (2011), un total de 15809 personnes a été affecté par l'événement. Le bilan humain s'élève à 498 personnes provisoirement évacuées, 305 personnes sans abri et 6 hospitalisées. Quant aux dommages matériels, 166 habitations, 10 édifices publics, 1 local associatif et 256 locaux commerciaux et artisanaux ont été endommagés, parmi lesquels 75 habitations ont été totalement détruites ; 6 véhicules ont également été détruits.

Parmi les dommages causés aux infrastructures civiles, il ressort que $500 \mathrm{~m}$ de l'Avenue José Alves de Figueiredo, qui longe le canal du Rio Granjeiro ont été détruits, ainsi que les trottoirs, les systèmes d'adduction d'eau et d'énergie attenants. S'ajoutent à ces dégâts, la dégradation ou la destruction partielle de 2 ponts de béton reliant les deux rives du chenal, ainsi que de 2 passerelles métalliques, de plusieurs transformateurs, et les pompes à essence d'une station-service à l'aval de la mairie (illustrations 13A à 13D). Le montant des dommages est évalué par la mairie à $3153000 \mathrm{R} \$(\sim 1,4 \mathrm{M}$ euros : résidences, commerces, marchandises) et $55529000 \mathrm{R} \$$ ( $\sim 22 \mathrm{M}$ euros : infrastructures). 
Illustrations 13A et 13B - Dommages causés en ville par la crue du 28 janvier 2011 : traces laissées par la violence de l'écoulement près du canal
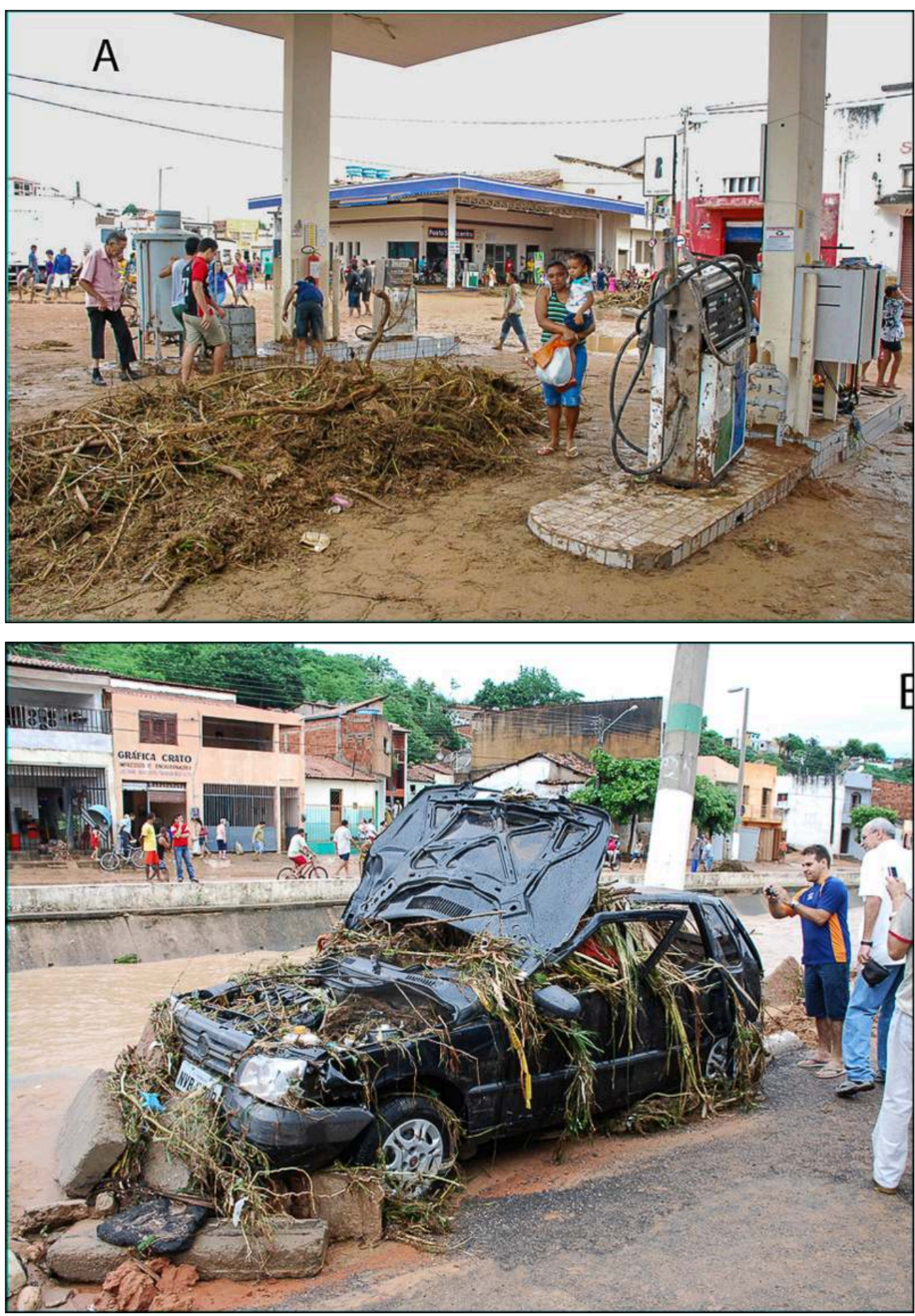

Auteurs : H. Maia et W. Veira. 
Illustrations 13C et $13 \mathrm{D}$ - Importance des dépôts boueux et la hauteur atteinte par l'eau dans les rues voisines
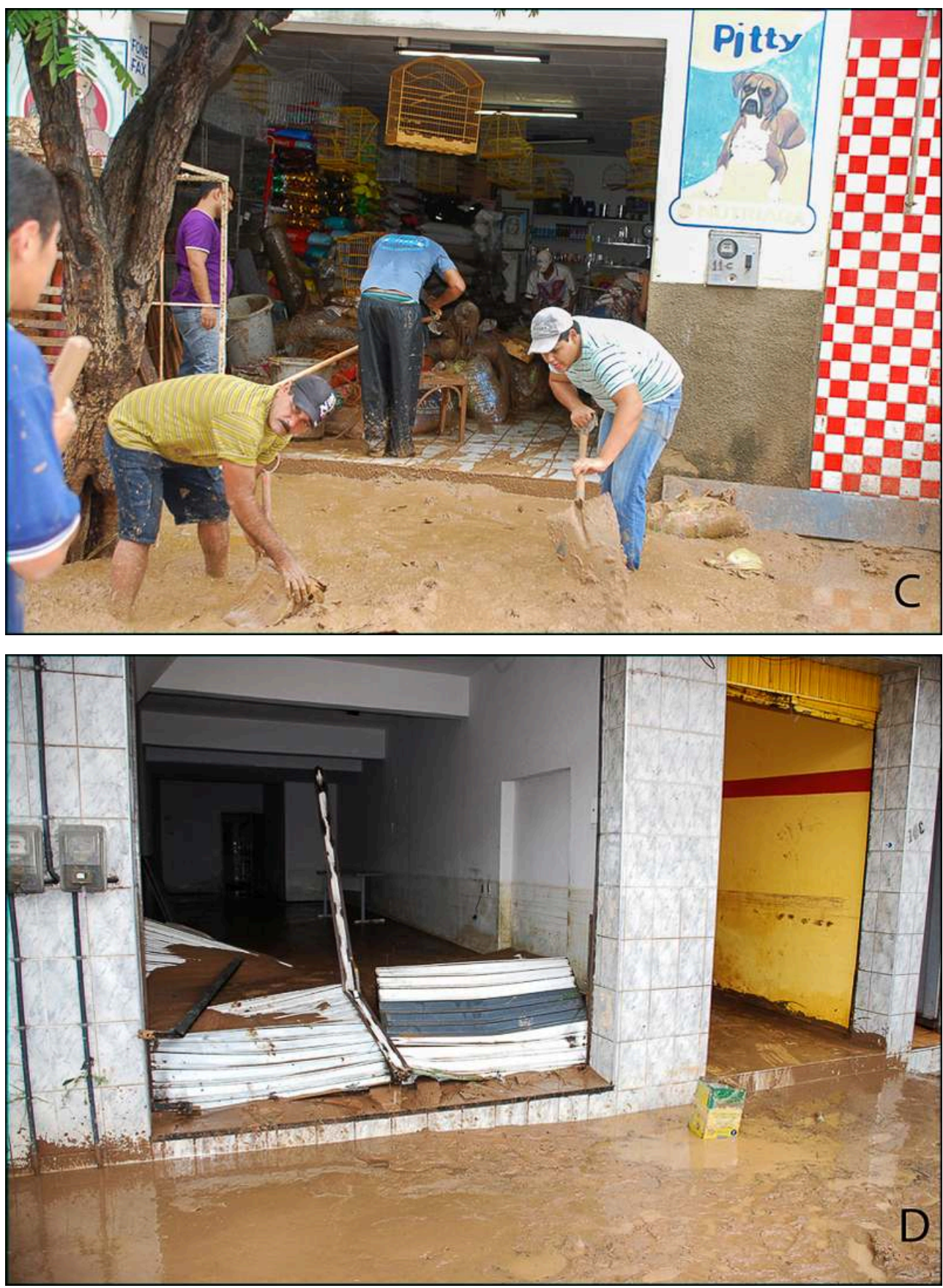

Auteurs : H. Maia et W. Veira.

Le jour suivant la crue, la mairie, la Défense Civile et le Corps de Pompiers ont transféré les familles touchées vers des abris d'urgence, des centres de soins, une résidence universitaire et des écoles. Différentes associations ont participé à une campagne de collecte de dons de nourriture, de vêtements, de couvertures, de médicaments, etc. Le Service d'Assistance sociale est intervenu avec des psychologues, des psychopédagogues et des infirmiers auprès des familles sans abri, fournissant un accompagnement psychologique, ainsi que des vaccins aux personnes qui avaient été directement en contact avec les eaux polluées. 
Il a également été procédé au recensement des familles sans abri, dans le but de mettre à leur disposition une aide financière appelée aluguel social, d'une valeur de $R \$ 120,00$ ( $\sim 50$ euros), pour que ces personnes puissent louer un logement dans une région plus sûre de la ville jusqu'à la baisse des eaux. Cependant, ce montant s'est révélé insuffisant, selon diverses personnes concernées, dans la mesure où les propriétaires ont profité de la situation pour augmenter les loyers...

Beaucoup de maisons, boutiques ou locaux artisanaux endommagés par la crue du 28 janvier 2011 restent menacés par de futurs événements de même magnitude. Les cas les plus graves sont ceux du Shopping Cariri, galerie commerçante proche du canal et régulièrement inondée, et surtout du Collège Objetivo, dont un grand bâtiment d'enseignement construit en marge de l'avenue de rive gauche est directement menacé par la destruction de la voirie et le recul de la berge (illustration 9B). Malgré cela, ces locaux restent occupés, car les habitants ne peuvent ou ne désirent pas, pour différents motifs (familiaux, professionnels, etc.), s'installer dans des secteurs plus sûrs mais aussi plus éloignés de la ville. Il s'avère également difficile ou impossible de transférer certaines activités ou certains équipements (collège...) représentant de lourds investissements et requérant la proximité du centre.

\section{Discussion : les risques naturels, une problématique scientifique nouvelle dans le Nordeste du Brésil?}

\section{Des phénomènes de moins en moins exceptionnels?}

La période pour laquelle des données relativement précises sont disponibles est courte : une dizaine d'années (depuis 2002). Elle correspond aussi à celle de l'achèvement du canal du Rio Grangeiro dans son extension et sa forme actuelle. Elle voit aussi la multiplication des problèmes liés à sa construction, à sa mauvaise qualité, à l'absence d'entretien et, surtout, à l'imprudente occupation de ses abords immédiats par toutes sortes d'habitations et d'implantations collectives dont certaines accueillent un public nombreux (collège Objetivo).

La compilation des données obtenues de la FUNCEME (précipitations), des autorités locales et des journaux fait apparaître la répétition quasi-annuelle de crues-éclair et d'inondations, au rythme moyen d'un événement par an, toujours pendant la saison des pluies (janvier-avril : tableau 1). Dans cette série, la crue du 28 janvier 2011 n'apparaît donc pas comme un événement inhabituel, si ce n'est par l'ampleur des dégâts et du nombre de personnes concernées. Notons qu'une nouvelle crue accompagnée d'une inondation à peine moins importante est survenue l'année suivante, le 5 mars 2012, détruisant les réparations engagées en 2011 ainsi que de nouveaux segments du canal. Dans l'état actuel des connaissances, on ne sait pas si cette fréquence représente un changement par rapport à la situation antérieure, qui est celle d'une urbanisation moindre et d'un cours d'eau canalisé sur une longueur plus faible, limitée à la zone du centre-ville. 
Tableau 1 - . Evènements pluvieux et crues du Rio Grangeiro, 2002-2012

\begin{tabular}{|c|c|c|c|c|c|c|}
\hline année & $\begin{array}{l}\text { Source } \\
\text { information }\end{array}$ & date & $\begin{array}{l}\text { Pluie } \\
\text { Station } \\
\text { Crato } \\
(\mathrm{mm})\end{array}$ & $\begin{array}{l}\text { Pluie } \\
\text { Station } \\
\text { Lameiro } \\
(\mathrm{mm})\end{array}$ & Crue, inondation & $\begin{array}{l}\text { Autres pertes et } \\
\text { dommages }\end{array}$ \\
\hline 2002 & $\begin{array}{l}\text { DN } \\
\text { DN } \\
\text { JC }\end{array}$ & $\begin{array}{l}03 / 01 \\
25 / 01 \\
15 / 03\end{array}$ & $\begin{array}{l}61 \\
92,8\end{array}$ & & $\begin{array}{l}\text { Rio Grangeiro, marges du } \\
\text { canal } \\
\text { Dégradation du canal }\end{array}$ & $\begin{array}{l}95 \text { maisons détruites } \\
\text { (Batateira) }\end{array}$ \\
\hline 2003 & $\begin{array}{l}\text { DN } \\
\text { DN }\end{array}$ & $\begin{array}{l}19 / 01 \\
17 / 03\end{array}$ & $\begin{array}{l}120 \\
88\end{array}$ & $\begin{array}{l}36 \\
66\end{array}$ & $\begin{array}{l}\text { Débordement } \\
\text { dégradation du canal } \\
\text { Inondation Riacho da } \\
\text { Vala, Rua Tristão } \\
\text { Gonçalves }\end{array}$ & $\begin{array}{l}\text { Destruction de } \\
\text { maisons (Seminario) }\end{array}$ \\
\hline 2004 & DN & $\begin{array}{l}31 / 01 \\
16 / 02\end{array}$ & $\begin{array}{l}99 \\
156\end{array}$ & $\begin{array}{l}74 \\
136\end{array}$ & $\begin{array}{l}\text { Débordement canal et } \\
\text { Riacho da Vala, quartier } \\
\text { mairie, } 1 \mathrm{~km} 2 \text { inondé } \\
\text { Débordement canal et } \\
\text { Riacho da Vala }\end{array}$ & 2700 sans abri \\
\hline 2005 & DN & $24 / 03$ & 100 & 94 & $\begin{array}{l}\text { Débordement du canal, } 1 \\
\text { voiture emportée }\end{array}$ & $\begin{array}{l}1 \text { mort, } 96 \text { sans abri } \\
26 \text { maisons } \\
\text { détruites }\end{array}$ \\
\hline 2006 & DN & $21 / 04$ & 105 & 122 & $\begin{array}{l}\text { Débordement et } \\
\text { dégradation du canal, } \\
\text { inondation : prison, } 100 \\
\text { maisons, Praça da Sé }\end{array}$ & \\
\hline 2007 & DN & $11 / 04$ & 80 & 110 & $\begin{array}{l}\text { Dégradation du canal, } \\
\text { sans débordement }\end{array}$ & \\
\hline 2008 & DN & $\begin{array}{l}11 / 02 \\
24 / 03\end{array}$ & $\begin{array}{l}95 \\
71\end{array}$ & $\begin{array}{l}92 \\
90\end{array}$ & $\begin{array}{l}\text { Dégradation du canal } \\
\text { (partie neuve) et du pont } \\
\text { du Champ de tir } \\
\text { Inondation du bas de la } \\
\text { Praça da Sé, dégradation } \\
\text { du canal }\end{array}$ & \\
\hline 2009 & $\mathrm{DN}$ & 06/04 & 115 & 63 & $\begin{array}{l}\text { Inondation Riacho da } \\
\text { Vala }\end{array}$ & \\
\hline 2010 & $\mathrm{OP}$ & $31 / 01$ & 115 & & Inondation dans Crato & \\
\hline
\end{tabular}




\begin{tabular}{|c|c|c|c|c|c|c|}
\hline 2011 & $\begin{array}{l}\text { DN } \\
\text { OP }\end{array}$ & $28 / 01$ & 162 & 137 & $\begin{array}{l}\text { Débordement et } \\
\text { destruction partielle du } \\
\text { canal, } \\
\text { Inondation du centre } \\
\text { ville }\end{array}$ & $\begin{array}{l}\text { Destruction de ponts } \\
\text { et passerelles } \\
\text { Dégradation de la } \\
\text { voirie, inondation } \\
\text { de166 maisons et } 256 \\
\text { magasins, } \\
\text { destruction de } 75 \\
\text { maisons; } 305 \text { sans } \\
\text { abri }\end{array}$ \\
\hline 2012 & DN & $05 / 03$ & 92,8 & 85 & $\begin{array}{l}\text { Dégradation ou } \\
\text { destruction partielle du } \\
\text { canal (segments réparés) }\end{array}$ & \\
\hline
\end{tabular}

Source : Compilation à partir de la consultation de la presse (DN : Diario do Nordeste ; OP : O Povo ; JC : Jornal do Cariri) et des bulletins pluviométriques de la FUNCEME.

51 L'analyse des graphiques pluviométriques journaliers des stations de Crato (centreville) et Lameiro (un peu à l'amont du centre-ville) fait apparaitre des seuils de déclenchement de l'ordre de 70 à $90 \mathrm{~mm}$ tombés à Lameiro (généralement en 2 à 3 heures), quelles que soient les séquences pluviométriques antérieures; les inondations les plus graves surviennent pour des pluies supérieures à $100 \mathrm{~mm}$ dans les deux stations (elles restent moins marquées si la station de Lameiro reçoit moins). Avec ses $162 \mathrm{~mm}$ et $137 \mathrm{~mm}$ respectivement, la pluie du 28 janvier 2011 est la plus forte de toute la période considérée, ce qui justifie son traitement particulier. Elle aura coïncidé avec une aggravation de l'état du canal qui est sans doute indirectement l'autre grand responsable de l'inondation, dans la mesure où la présence du canal a pu donner l'illusion aux populations qu'elles étaient bien protégées.

\section{Des aléas aux risques : des phénomènes nouveaux liés à la croissance urbaine mal accompagnée}

52 L'analyse des facteurs aggravants a montré un rôle considérable des facteurs anthropiques dans le déclenchement des crues-éclair du Rio Grangeiro. Outre des aménagements hydrauliques mal appropriés, mal conçus et/ou mal construits, et mal entretenus, l'urbanisation elle-même comporte ses propres facteurs de risque, à la fois par un accroissement des vulnérabilités et des enjeux, et par une modification des aléas : construction dans des zones naturellement inondables ou devenues inondables par suite des aménagements, modification des conditions d'infiltration et de ruissellement dans des parties du bassin-versant susceptibles d'engendrer des écoulements accrus. Comme le remarquent de nombreux articles de presse et même les rapports officiels déjà cités, il est d'ores et déjà certain que l'accélération de l'urbanisation, l'occupation désordonnée des sols, ainsi que la négligence des administrations publiques, ont contribué à créer une situation toujours plus critique, pouvant entraîner dans le futur des catastrophes aux conséquences de plus en plus lourdes.

53 Parmi les facteurs les plus évidents, outre la géométrie inappropriée du canal, son état lamentable dans les années et les mois précédant la crue a été pointé par tous les 
observateurs et la population concernée, illustrant les retards des pouvoirs publics dans l'accompagnement et la planification de l'urbanisation. Depuis le début des années 2000, chaque crue a été suivie de promesses des autorités (commune, État) de régler " définitivement » le problème du "canal » (le cours d'eau en tant qu'élément naturel du milieu est oublié ou même nié) et de ses débordements. Les défauts de conception sont reconnus, l'absence d'entretien l'est moins. On reste surtout frappé par l'improvisation qui préside aux travaux censés régler le problème et qui semblent surtout répondre au souci de rassurer la population riveraine. Ainsi, dans les mois qui ont suivi la crue du 28 janvier 2011, les fonds débloqués par l'État (4 millions de reais, soit $1,6 \mathrm{M}$ euros) ont servi à des remblaiements partiels de certains des segments de parois détruits au moyen de gabions reposant directement sur le fond alluvial mis à nu, accompagnés de variations supplémentaires de profil transversal et de section (illustration $8 \mathrm{~B}$, illustrations $14 \mathrm{~A}$ et $14 \mathrm{~B})$. Inévitablement, ces réparations de fortune, faites sans aucune étude préalable, ont été mises à mal par la crue du 5 mars 2012 et ont même pu en aggraver les effets sur les berges déjà affouillées et privées de protection.

Illustration 14A - Réparations du canal du Rio Grangeiro après la crue du 28 janvier 2011 : à l'aval de l'église Nossa Senhora de Fátima

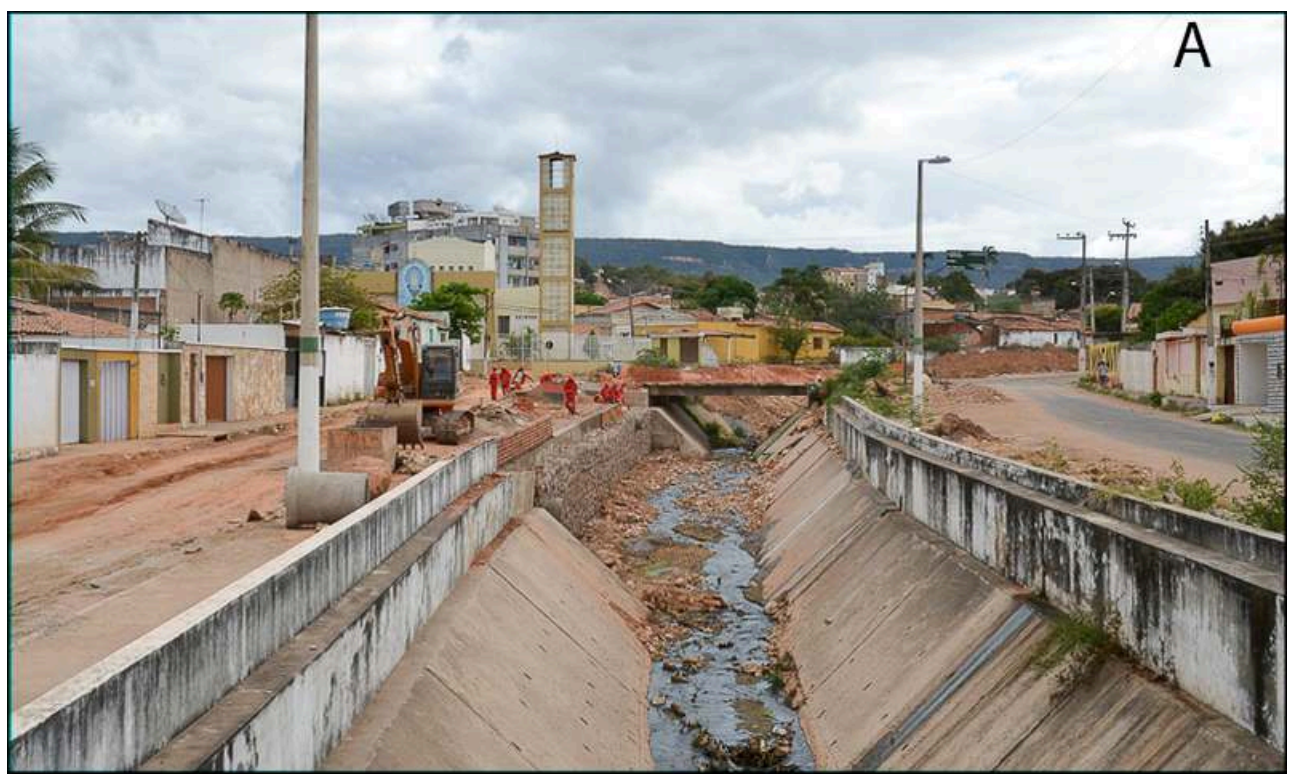

Auteur : JP. Peulvast, août 2011. 
Illustration 14B - Devant le collège Objetivo

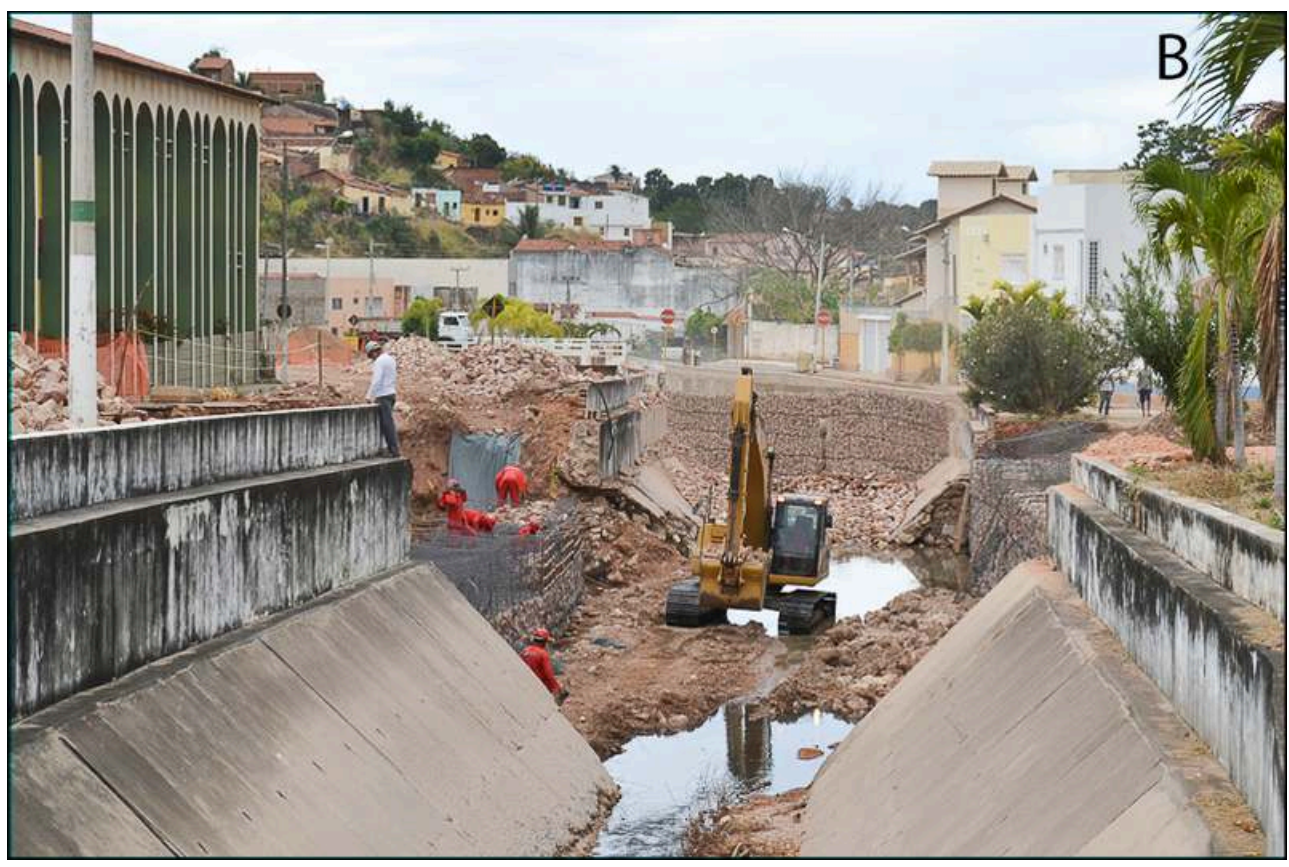

Pose de gabions à même le lit du cours d'eau dans les tronçons détruits par la crue de janvier 2011. Maintien de la section trapézoïdale ailleurs, ainsi que des ponts trop bas, induisant des variations de forme transversale et de calibre propices à une accentuation des turbulences et de la puissance érosive de l'écoulement de crue.

Auteur : JP. Peulvast, août 2011

Cependant, face à ces faits visibles par tous, les facteurs plus généraux tels que l'absence de gestion du bassin-versant à l'amont, l'absence de contrôle du respect des aires de protection environnementale et l'absence de réglementation des implantations dans les zones de risque (lesquelles ne sont d'ailleurs ni définies ni cartographiées dans aucun document), sont encore plus préoccupants. La prise en compte d'une approche scientifique et multidisciplinaire de ces problèmes n'en est que plus urgente.

\section{Approche scientifique et gestion des risques : comment passer de la connaissance géographique à la prévention et à l'aménagement urbain?}

La collecte de données effectuée pour la rédaction de cet article a fait apparaître leur caractère parcellaire. Sur le plan météorologique, seules deux stations fournissent des données régulières et fiables, depuis 1974 pour Crato et 1994 pour Lameiro (FUNCEME, 2013) ; celle de l'aéroport de Juazeiro do Norte, la seule à fournir des données horaires, est située à $15 \mathrm{~km}$. Il n'existe pas de système local d'alerte et un radar météo n'a été installé au Ceará qu'en mars 2011. On remarque surtout l'absence de données hydrologiques dans le bassin-versant et sur le drain principal. Aucune étude hydrologique ou même hydraulique n'a été faite avant la chenalisation du cours d'eau. De la même manière, les réparations d'urgence ont été faites sans aucune des études préalables qu'il est pourtant envisagé ou promis d'entreprendre au lendemain de chaque inondation. Les rapports consultés soulignent aussi l'absence de gestion coordonnée du bassin-versant mais aucune solution n'est proposée, l'urbanisation continuant et même s'accélérant pendant toute la décennie 2000, dans les vallées 
comme sur les interfluves. Au cours de la même décennie, est apparue l'idée de construire ou rétablir six retenues dans les parties amont du bassin-versant. Le Plano de Requalificação Urbana (PRU) de Crato établi en 2005 et révisé en 2009 en donne même la localisation approximative, sur le Rio Grangeiro et trois de ses affluents, dont le Riacho das Piabas et le Riacho da Vala, entre 1 et $2 \mathrm{~km}$ en amont du centre-ville (illustration 15). L'idée a fait ses preuves dans de nombreux cas comparables et dans d'autres pays (par exemple en France, dans des régions de plateaux disséqués ; Merckle \& Royet, 2010), mais dans le cas présent, il n'a pas été possible d'accéder aux documents d'ingénierie cités dans le PRU, ni aux éventuels chiffrages ou aux évaluations de faisabilité en termes fonciers. De même, il n'existe actuellement pas de données sur le taux de couverture et d'imperméabilisation des sols, données d'ailleurs mouvantes et difficiles à acquérir dans un contexte d'urbanisation rapide et de spéculation foncière. Les lotissements en construction ou récemment construits ne comportent pas de poches de rétention des eaux, ce qui montre là aussi l'absence de gestion des phénomènes de ruissellement. Seuls sont envisagés des ouvrages plus importants, sur les axes où les écoulements se sont déjà concentrés.

\section{Illustration 15 - Plan de requalification urbaine de Crato}

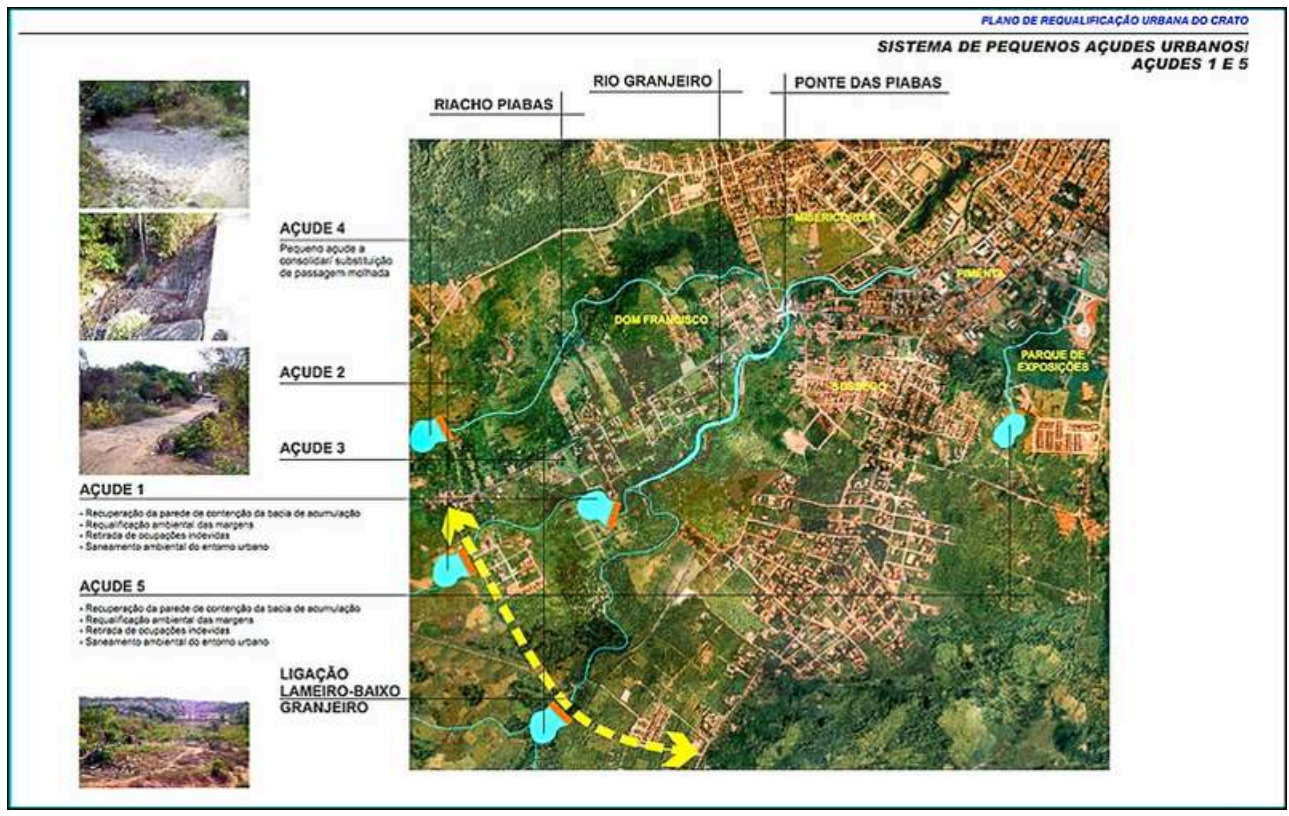

L'implantation des petites retenues (pequenos açudes) sont prévues pour retarder et atténuer les crues du Rio Grangeiro. Deux d'entre elles utiliseraient des parties surélevées de la liaison routière (ligação) Lameiro-Bas Grangeiro, à ce jour non réalisée.

Les raisons de cette situation sont sans doute à la fois juridiques et politiques. Mais elles tiennent aussi à l'absence de prise en compte du fonctionnement du milieu pris dans son ensemble, avec son relief, son substrat, son climat, sa végétation, ses types d'occupation des sols, etc. Le réseau hydrographique lui-même, ainsi que l'hydrologie, restent mal connus, sans véritable connaissance de leur état naturel ni des nombreuses modifications et perturbations d'origine anthropique. Une étude scientifique intégrée apparaît donc nécessaire et urgente, ce qui justifiera de futures investigations. 


\section{Conclusion}

La ville de Crato souffre fondamentalement de continuer à se développer sans respecter le cours d'eau qui la traverse. Le petit torrent montagnard qu'est le Rio Grangeiro est la plus grande partie de l'année tellement privé de son eau par les captages, qu'il en est oublié et que l'on a cru pouvoir le réduire à un ruisseau facilement contenu entre deux parois de béton. Il circule désormais dans un véritable toboggan aux lignes simplifiées mais irrégulières. Celui-ci n'a pour effet que d'accélérer l'écoulement et de l'acheminer au plus vite hors de la cité, jusque dans la plaine de confluence où on pourra l'oublier entre les champs de canne à sucre, là où il n'incommode personne... Ruisseau, mais aussi égout à ciel ouvert, devenant en saison sèche un filet noirâtre qui, serpentant de trou en fissure sur le fond cimenté, incommode riverains et passants. Et pourtant, pratiquement chaque année depuis ce corsetage inconsidéré, de violentes crues viennent rappeler que l'eau retrouve toujours son chemin et qu'elle peut toujours reprendre ses droits sur son ancienne plaine d'inondation, et même au-delà.

La question qui se pose est donc de savoir comment rendre au Rio Grangeiro son statut de rivière et composer avec des excès qui menacent de s'aggraver compte tenu de l'occupation croissante de son bassin-versant. La crue du 28 janvier 2011 est venue rappeler, après bien d'autres, que cette question est grave, qu'elle demande des solutions urgentes, mais aussi que celles-ci ne peuvent pas être élaborées dans l'improvisation et la dispersion. L'analyse des conditions de déclenchement et des conséquences de cette crue est un pas dans cette direction. Elle devra s'insérer dans une approche scientifique plus large et interdisciplinaire dont les résultats devraient s'articuler avec ceux des approches appliquées (ingénierie, urbanisme...) afin de fournir aux décideurs les éléments nécessaires à l'élaboration d'une planification urbaine comportant une véritable gestion des risques d'inondation et, plus généralement, des risques « naturels ». Parallèlement, la diffusion de ces résultats auprès de la population devrait améliorer la perception de cette situation, sans laquelle cette gestion peut rester incomprise, mal acceptée et inefficace.

\section{BIBLIOGRAPHIE}

Bétard F., 2007. Montagnes humides au cœur du Nordeste brésilien semi-aride : le cas du massif de Baturité (Ceará). Apports d'une approche morphopédologique pour la connaissance et la gestion des milieux. Thèse de doctorat, Université Paris-Sorbonne, $442 \mathrm{p}$.

Bravard J.P., Petit F., 1997. Les cours d'eau. Dynamique du système fluvial. Armand Colin, Paris, 222 p.

Carvalho S.M., Ribeiro S.M., 2007. Identificão das áreas de riscos de deslizamentos urbanos e periurbanos da cidade do Crato/CE. Cadernos de cultura e ciência, URCA, 2, p. 1-9.

Cavalcante A., 2005. Jardins suspensos no Sertão. Scientific American Brasil, 32, p. 69-73.

CPRM, 2005. Hidrogeologia da porção oriental da bacia sedimentar do Araripe. Rede Cooperativa de Pesquisa, Brasilia. 
Dauphiné A., 2001. Risques et catastrophes. Observer - Spatialiser - Comprendre - Gérer. Armand Colin, Paris, $288 \mathrm{p}$.

INPE, 2011. Análise sinótica : 28/01/2011-00Z. Boletim técnico. www.inpe.br, accès du 08/05/2012.

FUNCEME, 2011. Gráficos de chuvas dos postos pluviométricos. Postos Crato e Lameiro.

www.Funceme.br, accès du 15/05/2013.

FUNCEME, 2013. Download de séries históricas, Postos Crato e Lameiro. www.Funceme.br, accès du $12 / 02 / 2013$.

FUNDETEC, 1999. Mapa da Zona de Conservação e Desenvolvimento do Equilibrio Ambiental da Região Metropolitana CRAJUBAR. 1:50000. Crato.

Glastron S., 2003. Culture des risques. In V. Moriniaux (dir.), Les risques. Éditions du Temps, Nantes, p. 71-87.

Horton R.E.,1945. Erosional development of streams and their drainage basin. Hydrophysical approach to quantitative geomorphology. Geological Society of America Bulletin, 56, 3, p. 275-370.

Lima Neto' R.T., Mendonça' L.A.R., Pereira'J. A., Sousa'C.A.V., Gonçalves'J.Y.B., Frischkorn H., 2008. Análise morfométrica e ambiental da microbacia hidrográfica do rio Granjeiro, Crato/CE. Rev. Esc. Minas, 61, 3, p. 1-10.

Magalhães A.O., Peulvast J.P., Bétard F., 2010. Geodinâmica, perigos e riscos ambientais nas margens úmidas de planaltos tropicais: levantamento preliminar na região do Cariri oriental (Ceará, Brasil). vI Seminário Latino-Americano de Geografia Física-II Seminário Ibero-Americano de Geografia Física, Coimbra, abstract.

Melo A.B.C., 2011. As chuvas podem continuar escassas no extremo sul do Brasil. Infoclima, Boletim de Informações climáticas do CPTEC/INPE, ano 18, 1, 4 p.

Menad W., Douvinet J., Beltrando G., Arnaud-Fassetta G., 2012. Évaluer l'influence de l'urbanisation face à un aléa météorologique remarquable : les inondations des 9-10 novembre 2001 à Bab-el-Oued (Alger, Algérie). Géomorphologie, Relief, Processus, Environnement, 3, p. 337-350.

Merckle S., Royet P., 2010. Petits barrages de ralentissement dynamique en Seine Maritime. Principes de conception et de réalisation. CEMAGREF, $35 \mathrm{p}$.

Oliveira R.R. de, 2011. Danos ocasionados pelas chuvas ao longo do canal do Rio Grangeiro e da encosta do Bairro Seminário (Relatório Técnico). GEOSOMA - Geologia, Sondagens e Meio Ambiente Ltda. Crato, $17 \mathrm{p}$.

PDM Crato, 2009 - Plano Diretor Municipal, 2009. Leitura Técnica/Caracterização. Crato, 208 p.

Peulvast J.P., Bétard F., Magalhães A.O., 2011. Scarp morphology and identification of large-scale mass movements in tropical tablelands: the eastern Araripe basin (Ceará, Brazil). Géomorphologie : relief, processus, environnement, 1, p. 33-52.

Ribeiro S.C., 2004. Susceptibilidade aos Processos Erosivos Superficiais com Base na Dinâmica Geomorfológica na Microbacia do Rio Grangeiro, Crato/CE. Dissertação de Mestrado, Rio de Janeiro: $\mathrm{UFRJ} / \mathrm{PPGG}$.

Ribeiro S.C., Guerra A.J., 2003. Fatores sócio-ambientais na aceleração de processos erosivos em áreas urbanas: o bairro Seminário, Crato/CE. Revista do Departamento de Geografia - Geo UERJ, $\mathrm{n}^{\circ}$ especial, p. 1827-1829.

Shreve R.L., 1966. Statistical law of stream numbers. Journal of Geology, 74, p. 17-37. 
Silva F.O.E. da, 2011 a. Relatório de visita técnica e parecer preliminar sobre o evento hidrológico de enxurrada e os colapsos estruturais ocorridos no canal do Rio Granjeiro na cidade do Crato no mês de Janeiro/2011. Universidade Federal do Ceará, Departamento de Engenharia Hidráulica e Ambiental, Fortaleza, 13 p.

Silva F.O.E. da, 2011 b. Laudo técnico de vistoria das obras de recuperação do canal do rio granjeiro na cidade do Crato durante o evento chuvoso de 19/10/2011. Prefeitura Municipal do Crato, Secretaria de Infraestrutura e Serviço Urbano, Crato, $34 \mathrm{p}$.

Soares R.C., 2006. Carta de Cadastro das Cicatrizes de Feições Erosivas e Movimentos Gravitacionais de Massa nas Áreas Urbanas e Periurbanas de Barbalha/CE com vistas ao Planejamento Urbano-Ambiental. Anais do VI Simpósio Nacional de Geomorfologia/Regional Conference on Geomorphology, Goiânia.

Sousa C.A.V., Mendonça, L.A.R., Gonçalves J.Y.B., 2006. Análise preliminar de riscos ambientais devido a expansão urbana na micro-bacia hidrográfica do Rio Granjeiro no município do Crato CE. VIII Simpósio Italo Brasileiro de Engeniaria sanitária e ambiental, Fortaleza, CE, Anais.

Strahler A.N. 1957. Quantitative analysis of watershed geomorphology. Transactions of the American Geophysical Union, 38, 6, p. 913-920.

SUDENE-ASMIC, 1967. Estudo geral de base do vale do Rio Jaguaribe. Vol. IV. Hidrologia. GVJ, Brasilia.

\section{RÉSUMÉS}

La crue du Rio Grangeiro qui s'est produite à Crato (Ceará) le 28 janvier 2011, est un exemple des événements brutaux qui menacent de plus en plus les biens, les infrastructures et les personnes dans le Nordeste brésilien. Malgré la répétition récente d'inondations catastrophiques, ici et dans d'autres régions du Brésil, la problématique des risques naturels n'apparaît guère dans l'aménagement et la planification urbaine. Bien plus fréquentes que les grands mouvements de masse récemment reconnus dans le rebord de la Chapada do Araripe, les crues et, en particulier, les crues-éclair, restent pourtant mal étudiées, en dépit des nombreuses déclarations faites après chaque inondation. L'objectif est donc de contribuer à combler cette lacune, à partir d'une étude de cas portant sur l'événement cité. Après une présentation du secteur étudié et des méthodes utilisées, l'article décrit cette crue violente, ses causes et ses conséquences, puis analyse les facteurs naturels et anthropiques en cause, en particulier les effets d'une canalisation inadaptée du torrent. Il aboutit à une réflexion sur le caractère de moins en moins exceptionnel de tels événements dans le contexte d'une urbanisation mal contrôlée qui modifie la formation et les modalités des écoulements, tout en aggravant les menaces sur les biens et les personnes. Notre réflexion porte aussi sur le rôle que peut jouer la connaissance géographique par rapport à la prise en compte de la question des risques naturels dans le processus d'urbanisation à l'intérieur du Nordeste brésilien.

The catastrophic flood of the Grangeiro River, which seriously damaged the city of Crato (Ceará) on January $28^{\text {th }} 2011$, is a good example of the sudden events, which threaten properties, infrastructures and lives in Northeast Brazil. In spite of the repeated occurrence of such catastrophes here as well as in other regions of Brazil, the problematics of natural hazards and risks does not really appear in management and urban planning. Being more frequent than the large-scale mass movements recently discovered in the rim of the Chapada do Araripe, the floods, particularly flash floods, remain poorly studied and treated, in spite of the numerous announces repeated after each flood. Therefore our aim is to collect information on these events, through a case study bearing on the cited event. After a presentation of the study area and of the 
methodology, the article describes this violent flood, its conditions of occurrence and its consequences, and analyzes the natural and anthropogenic triggering factors, among them an inadequate canalization of the torrent. It demonstrates the less and less exceptional character of such events in the context of a poorly controlled urbanization, which modifies the formation and conditions of water runoff, and worsens the threats on properties and lives. We also show how important is the geographical knowledge for taking into account the natural hazard and risk problematics in the urbanization process of the Brazilian « Nordeste».

\section{INDEX}

Mots-clés : crue-éclair, inondation, canalisation, gestion des risques, urbanisation Keywords : flash flood, inundation, canalization, risk management, urbanization.

\section{AUTEURS}

\section{ALEXSANDRA DE OLIVEIRA MAGALHÃES}

Alexsandra de Oliveira Magalhães, alexsandra_oliveiramagalhaes@yahoo.com.br, est doctorante de l'UMR PRODIG, Université Paris-Diderot, Universidade Regional do Cariri (URCA), Crato, Ceará, Brésil.

\section{JEAN-PIERRE PEULVAST}

Jean-Pierre Peulvast, jean-pierre.peulvast@paris-sorbonne.fr, est professeur des universités à l'Université Paris-Sorbonne et membre du Laboratoire de Géographie Physique, CNRS UMR 8591. 